\title{
Identification of Novel phoP-phoQ Regulated Genes that Contribute to Polymyxin B Tolerance in Pseudomonas aeruginosa
}

\author{
Baopeng Yang, Chang Liu, Xiaolei Pan, Weixin Fu, Zheng Fan, Yongxin Jin, Fang Bai, Zhihui Cheng \\ and Weihui $\mathrm{Wu} * \mathbb{D}$
}

check for updates

Citation: Yang, B.; Liu, C.; Pan, X.; Fu, W.; Fan, Z.; Jin, Y.; Bai, F.; Cheng, Z.; Wu, W. Identification of Novel phoP-phoQ Regulated Genes that Contribute to Polymyxin B Tolerance in Pseudomonas aeruginosa. Microorganisms 2021, 9, 344. https:// doi.org/10.3390/microorganisms 9020 344

Academic Editor: José Luis Martínez

Received: 21 January 2021

Accepted: 8 February 2021

Published: 9 February 2021

Publisher's Note: MDPI stays neutral with regard to jurisdictional claims in published maps and institutional affiliations.

Copyright: (c) 2021 by the authors. Licensee MDPI, Basel, Switzerland. This article is an open access article distributed under the terms and conditions of the Creative Commons Attribution (CC BY) license (https:// creativecommons.org/licenses/by/ $4.0 /)$.
State Key Laboratory of Medicinal Chemical Biology, Key Laboratory of Molecular Microbiology and Technology of the Ministry of Education, Department of Microbiology, College of Life Sciences, Nankai University, Tianjin 300071, China; g8_1980530@outlook.com (B.Y.); liuchangbarry@gmail.com (C.L.); pxlay@hotmail.com (X.P.); 1120200520@mail.nankai.edu.cn (W.F.); jmy@xnmsn.com (Z.F.); yxjin@nankai.edu.cn (Y.J.); baifang1122@nankai.edu.cn (F.B.); zhihuicheng@nankai.edu.cn (Z.C.)

* Correspondence: wuweihui@nankai.edu.cn

Abstract: Polymyxin B and E (colistin) are the last resorts to treat multidrug-resistant Gram-negative pathogens. Pseudomonas aeruginosa is intrinsically resistant to a variety of antibiotics. The PhoPPhoQ two-component regulatory system contributes to the resistance to polymyxins by regulating an arnBCADTEF-pmrE operon that encodes lipopolysaccharide modification enzymes. To identify additional PhoP-regulated genes that contribute to the tolerance to polymyxin $\mathrm{B}$, we performed a chromatin immunoprecipitation sequencing (ChIP-Seq) assay and found novel PhoP binding sites on the chromosome. We further verified that PhoP directly controls the expression of PA14_46900, PA14_50740 and PA14_52340, and the operons of PA14_11970-PA14_11960 and PA14_52350-PA14_52370. Our results demonstrated that mutation of PA14_46900 increased the bacterial binding and susceptibility to polymyxin B. Meanwhile, mutation of PA14_11960 (papP), PA14_11970 ( $m p l)$, PA14_50740 (slyB), PA14_52350 (ppgS), and PA14_52370 (ppgH) reduced the bacterial survival rates and increased ethidium bromide influx under polymyxin B or Sodium dodecyl sulfate (SDS) treatment, indicating roles of these genes in maintaining membrane integrity in response to the stresses. By 1-N-phenylnaphthylamine (NPN) and propidium iodide (PI) staining assay, we found that $p a p P$ and $s l y B$ are involved in maintaining outer membrane integrity, and $\mathrm{mpl}$ and $p p g S-p p g H$ are involved in maintaining inner membrane integrity. Overall, our results reveal novel PhoP-PhoQ regulated genes that contribute to polymyxin B tolerance.

Keywords: polymyxin B; Pseudomonas aeruginosa; PhoP-PhoQ; membrane integrity

\section{Introduction}

Pseudomonas aeruginosa is an opportunistic Gram-negative bacterial pathogen that causes various infections in immunocompromised patients, including those suffering from acquired immune deficiency syndrome (AIDS), cancer, burn injury, and cystic fibrosis (CF) [1,2]. P. aeruginosa is intrinsically resistant to a variety of antibiotics [3]. The resistant mechanisms include low membrane permeability, multidrug efflux systems as well as chromosome encoded or horizontally acquired antibiotic breakdown or modification enzymes [4-6]. In addition, formation of biofilm drastically enhances the bacterial resistance to antibiotics [7]. Polymyxin B and colistin (polymyxin E) are cyclic polypeptide antibiotics that are used as the last-resort treatment option against serious infections caused by Gram-negative bacteria, including P. aeruginosa, Klebsiella pneumoniae, and Acinetobacter baumannii [7-10]. Polymyxin B and colistin are very similar in their structures, both consisting of a cyclic heptapeptide, a linear tripeptide, and a fatty acid chain [11]. The only difference between polymyxin B and colistin is an amino acid in the heptapeptide ring, with a leucine in colistin and a phenylalanine in polymyxin B [12]. The hydrophilic 
and hydrophobic regions of polymyxin B and colistin are essential for their antimicrobial activity [13]. The positively-charged polymyxins bind to the negatively-charged phosphate groups of lipopolysaccharide (LPS) on the Gram-negative bacteria surface [14]. Then the fatty acid chain of the polymyxin is inserted into the bacterial outer membrane (OM), increasing the membrane permeability and facilitating the passage of the polymyxin through the outer membrane [15]. Subsequently, the polymyxin damages the integrity of the bacterial inner membrane (IM) [16]. In addition, polymyxins have been demonstrated to inhibit NADH-quinone oxidoreductases on the bacterial cell membrane and interfere with cell division [17].

In $P$. aeruginosa, the two-component regulatory system PhoP-PhoQ is involved in the bacterial resistance to polymyxins [18]. The $p h o P-p h o Q$ genes forms an operon with an outer membrane porin gene oprH (oprH-phoP-phpQ), which is positively regulated by PhoP [19]. Under low- $\mathrm{Mg}^{2+}$ environments, the phosphorylated PhoP directly controls target gene expression by binding to a conserved sequence in the promoter region. The sensor protein PhoQ functions as a phosphatase that dephosphorylates the cognate response regulatory protein PhoP [20]. Thus, defect in the $p h o Q$ gene results in constitutive expression of the PhoP regulated genes [21]. PhoP directly binds to the promoter region of the oprH-phoP-phoQ operon and activates its transcription [19]. The high-level expression of OprH facilitates the uptake of divalent cations [22]. In addition to its own operon, PhoP has been found to regulate multiple genes that are involved in transmembrane transport, LPS modification, antibiotic and antimicrobial peptides resistance, as well as bacterial virulence [23-25]. In P. aeruginosa the lipid A can be covalently modified through addition of 4-amino-4-deoxy-L-arabinose (L-Ara4N) by enzymes encoded by the arnBCADTEF operon [26], which decreases the negative charge of the lipid A and thus reduces the binding of polymyxin [27]. PhoP-PhoQ and other two-component regulatory system, PmrA-PmrB, CprR-CprS, BqsR-BqsS, and ParR-ParS directly control the expression of the arnBCADTEF operon [28-30]. In addition, PhoP-PhoQ regulates the expression of pagP (PA14_46900) that contributes to the palmitoylation of lipid A [31]. A previous transcriptomic analysis on a $p h o P$ mutant revealed that PhoP positively regulates multiple genes, including $g a b D, g a b T$, PA0921, PA1343, PA3885 and the PA4010-PA4011 and PA4456-PA4453 operons, and negatively regulates the expression of PA1196, PA3309 and PA4918 [32,33]. Electrophoretic mobility shift assay (EMSA) results demonstrated a direct regulation of PA0921 and PA1343 by PhoP [33]. Loss of function mutations in the phoQ gene have been identified in P. aeruginosa strains from cystic fibrosis receiving inhaled colistin treatment, which contribute to high level resistance to polymyxins [27]. Mutation of $p h o Q$ in a wildtype reference strain PAO1 reduced the bacterial twitching motility, biofilm formation, cytotoxicity as well as virulence in a lettuce leaf and a chronic rat lung infection models [34]. These results demonstrate a global regulatory role of the PhoP-PhoQ system. However, genes directly regulated by $\mathrm{PhoP}$ and their roles in the bacterial resistance to polymyxin $\mathrm{B}$ remains to be explored.

In this study, a ChIP-Seq assay was used to identify genes that are directly regulated by PhoP. We further studied the roles and functional mechanisms of those genes in the bacterial tolerance to polymyxin B. Our results revealed novel genes regulated by the PhoP-PhoQ two-component regulatory system and advanced our understanding of the polymyxin B tolerance determinants in P. aeruginosa.

\section{Materials and Methods}

\subsection{Chemicals, Bacterial Strains, and Plasmids}

Bacteria were cultured in Luria-Bertani (LB) broth $(10 \mathrm{~g} / \mathrm{L}$ tryptone, $5 \mathrm{~g} / \mathrm{L}$ yeast extract and $5 \mathrm{~g} / \mathrm{L} \mathrm{NaCl}, \mathrm{pH}$ 7.0-7.5), cation adjusted Mueller-Hinton broth (CA-MHB) (Mueller-Hinton broth dry powder (Oxoid, Basingstoke, Hampshire, England) $21 \mathrm{~g} / \mathrm{L}$, $\mathrm{CaCl}_{2} 55.5 \mathrm{mg} / \mathrm{L}, \mathrm{MgCl}_{2} \cdot 6 \mathrm{H}_{2} \mathrm{O} 42 \mathrm{mg} / \mathrm{L}$, $\mathrm{pH}$ 7.0-7.5), second basal medium (BM2) (0.03 M glucose, $0.04 \mathrm{M} \mathrm{K}_{2} \mathrm{HPO}_{4}, 0.022 \mathrm{M} \mathrm{KH}_{2} \mathrm{PO}_{4}$, and $\left.0.007 \mathrm{M}\left(\mathrm{NH}_{4}\right)_{2} \mathrm{SO}_{4}, \mathrm{pH} 7.0\right)$, M9 medium (15.12 g/L Na $2 \mathrm{HPO}_{4} \cdot 12 \mathrm{H}_{2} \mathrm{O}, 3.0 \mathrm{~g} / \mathrm{L} \mathrm{KH}_{2} \mathrm{PO}_{4}, 0.5 \mathrm{~g} / \mathrm{L} \mathrm{NaCl}, 1.0 \mathrm{~g} / \mathrm{L} \mathrm{NH}{ }_{4} \mathrm{Cl}, 0.492 \mathrm{~g} / \mathrm{L}$ 
$\mathrm{MgSO}_{4} \cdot 7 \mathrm{H}_{2} \mathrm{O}$ and $3.94 \mathrm{~g} / \mathrm{L}$ succinic acid, $\mathrm{pH}$ 7.0) or on LB agar (LB broth containing $15 \mathrm{~g} / \mathrm{L}$ agar) at $37{ }^{\circ} \mathrm{C}$ aerobically. The bacterial strains and plasmids used in this study were listed in Table S2.

\subsection{RNA Extraction, Reverse Transcription, and Quantitative Real-Time PCR}

Bacteria were grown overnight in $\mathrm{LB}$ at $37^{\circ} \mathrm{C}$. The culture was diluted 1:100 in fresh LB and grown to an $\mathrm{OD}_{600}$ of 0.8. Total RNA was isolated with a Bacteria Total RNA kit (Zomanbio, Beijing, China) and the RNA concentration was determined with a NanoDrop spectrophotometer (Thermo Scientific, Waltham, MA, USA). cDNA was synthesized by using primeScript Reverse Transcriptase (TaKaRa, Dalian, China). The cDNA was then mixed with specific primers (Table S3) and an SYBR Premix ExTaq II (TaKaRa, Dalian, China). Quantitative real-time PCR was performed with a CFX Connect real-time system (Bio-Rad, Hercules, CA, USA). The $30 \mathrm{~S}$ ribosomal protein gene $r p s L$ was used as an internal control [35].

\subsection{Construction of lacZ Transcriptional Fusions and $\beta$-Galactosidase Activity Measurement}

Fragments of the promoter regions of the indicated genes were amplified by PCR with primers listed in Table S3, using PA14 chromosomal DNA as the template. The PCR products were cloned into the SmaI-HindIII sites of the plasmid pUCP20-lacZ [36]. The resulting plasmid was transferred into the indicated strains. The strains were grown to an $\mathrm{OD}_{600}$ of 0.8 . Bacterial cells from $0.5 \mathrm{~mL}$ culture were collected by centrifugation and resuspended with $1.5 \mathrm{~mL} \mathrm{Z} \mathrm{Buffer}\left(60 \mathrm{mM} \mathrm{Na}_{2} \mathrm{HPO}_{4}, 60 \mathrm{mM} \mathrm{NaH}_{2} \mathrm{PO}_{4}, 10 \mathrm{mM} \mathrm{KCl}, 1 \mathrm{mM}\right.$ $\mathrm{MgSO}_{4}, 50 \mathrm{mM} \beta$-mercaptoethanol, pH 7.0; BBI LifeScience, Shanghai, China). One mL of the bacterial suspension was used to measure $\mathrm{OD}_{600}$. The remaining $500 \mu \mathrm{L}$ suspension was mixed with $10 \mu \mathrm{L} 0.1 \%$ SDS and $10 \mu \mathrm{L}$ chloroform (BBI LifeScience, Shanghai, China) by vortex for $10 \mathrm{~s}$. Then $100 \mu \mathrm{L}$ O-nitrophenyl- $\beta$-D-galactopyranoside (ONPG, $40 \mathrm{mg} / \mathrm{mL}$; Sigma, USA) was added to the mixture and incubated at $37^{\circ} \mathrm{C}$. When the color of the mixture turned yellow, the reaction was stopped by addition of $500 \mu \mathrm{L}$ of $1.0 \mathrm{M} \mathrm{Na}_{2} \mathrm{CO}_{3}$. The reaction time was recorded. The mixture was subjected to centrifugation at $12,000 \times g$ for $1 \mathrm{~min}$, then $\mathrm{OD}_{420}$ of the supernatant was measured with a spectrometer (Bio-Rad). The $\beta$-galactosidase activity (Miller units) was calculated as $\left(1000 \times \mathrm{OD}_{420}\right) /\left(\mathrm{T} \times \mathrm{V} \times \mathrm{OD}_{600}\right)$. $\mathrm{T}$ : Reaction time ( $\mathrm{min})$; V: the bacterial sample volume $(\mathrm{mL})$.

\subsection{ChIP-Seq and Data Analysis}

To construct C-terminus FLAG tagged $p h o P$, the $p h o P$ coding region was amplified by PCR using PA14 chromosomal DNA as the template with primers listed in Table S2. The FLAG tag coding sequence was included in the primer annealing to the $3^{\prime}$ end of the $p h o P$ gene. The resulting PCR product was cloned into the BamHI and PstI sites of the plasmid pUCP20, resulting in pUCP20-phoP-FLAG.

The ChIP-Seq experiment and data analysis were performed by Wuhan IGENEBOOK Biotechnology Co., Ltd. PA14 containing the pUCP20-phoP-FLAG was grown in LB to an $\mathrm{OD}_{600}$ of 1.0. Formaldehyde was added to the culture at the concentration of $1 \%$ for $10 \mathrm{~min}$ at $37^{\circ} \mathrm{C}$ with continuous shaking for crosslinking. A total of $125 \mathrm{mM}$ glycine was added to the medium to stop the crosslinking. The bacterial cells were collected by centrifugation and washed twice a Tris buffer $(20 \mathrm{mM}$ Tris- $\mathrm{HCl} \mathrm{pH} 7.5,150 \mathrm{mM} \mathrm{NaCl})$ containing a complete proteinase inhibitor cocktail (Roche). Then the cells were incubated in $400 \mu \mathrm{L}$ nuclei lysis buffer (50 mM Tris-Hcl (PH8.0), 1\% SDS, 1\% Triton X-100, 10 mM ethylene diamine tetraacetic acid (EDTA), mini-protease inhibitor cocktail (Roche)) for $30 \mathrm{~min}$. The chromosomal DNA was sonicated to the sizes of 200-500 bp (20-s with 30-s interval, 15 cycle, Diagenode Bioruptor pico), followed by centrifugation at $14,000 \times g$ at $4{ }^{\circ} \mathrm{C}$ for $10 \mathrm{~min}$. Ten microliters $(10 \mu \mathrm{L})$ of the supernatant was used as input. Ten micrograms $(10 \mu \mathrm{g})$ of anti-Flag antibody (MAB 3118) was incubated with $100 \mu \mathrm{L}$ of the supernatant for $16 \mathrm{~h}$ at $4{ }^{\circ} \mathrm{C} .30 \mu \mathrm{L}$ protein $\mathrm{G}$ magnetic beads (Life Technologies, Carlsbad, CA, USA) was added to the supernatant and incubated at $4{ }^{\circ} \mathrm{C}$ for $2 \mathrm{~h}$ with gentle shaking. The beads 
were then washed sequentially with a low salt wash buffer $(20 \mathrm{mM}$ Tris- $\mathrm{HCl}, 150 \mathrm{mM}$ $\mathrm{NaCl}, 1 \%$ TritonX-100, 0.1\% SDS, 2 mM EDTA, pH8.1), a high salt wash buffer (20 mM Tris-HCl, $500 \mathrm{mM} \mathrm{NaCl}$, 1\% TritonX-100, 0.1\% SDS, 2 mM EDTA, pH8.1), a LiCl wash buffer $(0.25 \mathrm{M} \mathrm{LiCl}, 10 \mathrm{mM}$ Tris-HCl, 1\% sodium deoxycholate, 1\% NP40, 1 mM EDTA, $\mathrm{pH} 8.1$ ), and TE buffer (1 mM EDTA, $10 \mathrm{mM}$ Tris-HCl, $\mathrm{pH}$ 8). The protein-DNA complex was eluted by $400 \mu \mathrm{L}$ elution buffer $\left(0.1 \mathrm{M} \mathrm{NaHCO}_{3}, 1 \%\right.$ SDS), followed by incubation at $65^{\circ} \mathrm{C}$ for $20 \mathrm{~min}$. Then $20 \mu \mathrm{L}$ of $5 \mathrm{M} \mathrm{NaCl}$ was added to $400 \mu \mathrm{L}$ of the elute and incubated at $65{ }^{\circ} \mathrm{C}$ overnight to reverse the cross-linking, followed by incubation with $20 \mathrm{mg} / \mathrm{mL}$ Proteinase $\mathrm{K}$ in $30 \mathrm{mM}$ Tris- $\mathrm{HCl}$ and $10 \mathrm{mM}$ EDTA (pH 6.5) at $45^{\circ} \mathrm{C}$ for $1 \mathrm{~h}$. The DNA was isolated by phenol/chloroform/isoamyl extraction. The 250-350 bp DNA fragments were selected by SPRI beads. After repair and adaptor ligation, the DNA was amplified by PCR for 15 cycles. The library was sequenced with the HiSeq 2000 system (Illumina) for $50 \mathrm{nt}$ single-end sequencing. Totally 38,494,074 and 50,472,658 reads were obtained from the input and ChIP samples, respectively. Low-quality reads were filtered out with Trimmomatic (v. 0.38), resulting in 32,663,770 and 43,214,422 clean reads of the input and ChIP samples, respectively. The clean reads were mapped to the PA14 genome by Bwa (v. 0.7.15). Potential PCR duplicates were removed with the software Samtools (v. 1.3.1). The software MACS2 (v. 2.1.1.20160309) was used to call peaks by default parameters (model fold, 5, 50; bandwidth, $300 \mathrm{bp}$; q value, 0.05).

\subsection{Expression and Purification of the $6 \times$ His-Tagged PhoP Protein}

The phoP gene was amplified by PCR with primers listed in Table S3 and cloned into the plasmid pET28a, resulting in a C-terminal $6 \times$ His-tagged phoP ( $p h o P$-His). The cloned fragment was verified by sequencing performed by GENEWIZ Corporation (Suzhou, China). The plasmid was transferred into an E. coli strain BL21 (DE3). The bacteria were grown in $\mathrm{LB}$ to an $\mathrm{OD}_{600}$ of 0.6 , followed by induction with $0.2 \mathrm{mM}$ isopropyl- $\beta$ D-thiogalactoside (IPTG) for $5 \mathrm{~h}$ at $37{ }^{\circ} \mathrm{C}$ with agitation at $200 \mathrm{rpm}$. The bacteria were harvested by centrifugation at $4{ }^{\circ} \mathrm{C}$. The pellet was resuspended with a cold lysis buffer $\left(50 \mathrm{mM} \mathrm{Na}_{2} \mathrm{HPO}_{4}, 50 \mathrm{mM} \mathrm{NaH} \mathrm{PO}_{4}, 0.3 \mathrm{M} \mathrm{NaCl}\right)$. After sonication on ice, the mixture was subjected to centrifugation at $10,000 \times g$ for $10 \mathrm{~min}$ at $4{ }^{\circ} \mathrm{C}$. The supernatant was collected and mixed with the Ni-nitrilotriacetic acid (NTA) beads (Qiagen, Düsseldorf, North Rhine-Westphalia, GER) and incubated at $4{ }^{\circ} \mathrm{C}$ for $2 \mathrm{~h}$ with gentle shaking. The beads were washed three times with the lysis buffer containing $20 \mathrm{mM}$ imidazole. The bound protein was eluted with the lysis buffer containing $300 \mathrm{mM}$ imidazole and examined by SDS-PAGE.

\subsection{EMSA}

Sequences of the DNA probes are listed in Table S3. DNA fragments (200 ng) were incubated with $0,2,4$ or $8 \mu \mathrm{M}$ purified His-tagged PhoP in a 20- $\mu \mathrm{L}$ binding reaction system [50 mM Tris, pH 7.9, 50 mM NaCl, 0.5 mM EDTA, 10\% glycerol, 1\% (v/v) NP-40 (Solarbio, Beijing, China)] at room temperature for $30 \mathrm{~min}$ [37]. The binding mixtures were loaded onto an $8 \%$ native polyacrylamide gel in $1 \times$ Tris-borate-EDTA (TBE) buffer $(0.044 \mathrm{M}$ Tris, $0.044 \mathrm{M}$ boric acid, $0.001 \mathrm{M}$ EDTA, $\mathrm{pH}$ 8.0) that had been pre-run on ice at $100 \mathrm{~V}$ for $1 \mathrm{~h}$. The electrophoresis was performed on ice at $100 \mathrm{~V}$ for $75 \mathrm{~min}$. The gel was stained with ethidium bromide in 1×TBE buffer for 5-10 min. The bands were visualized with a molecular imager ChemiDoc TM XRS+ (Bio-Rad, Hercules, CA, USA).

\subsection{Minimum Inhibitory Concentration (MIC) Measurement}

Bacteria of the indicated strains were diluted to $1 \times 10^{5} \mathrm{CFU} / \mathrm{mL}$ in LB or CA-MHB, and added into each well of a 96-well plate $(150 \mu \mathrm{L} /$ well). Antibiotics with appropriate concentrations were added into the first row of the plate, followed by a serial two-fold dilution. The plate was incubated at $37^{\circ} \mathrm{C}$ for $24 \mathrm{~h}$. The lowest antibiotic concentration that inhibited visible growth was recorded as the MIC. 


\subsection{Bacterial Survival Assay}

Overnight bacterial cultures were diluted 100-fold in fresh medium and grown to an $\mathrm{OD}_{600}$ of 1.0. The bacteria were diluted to $4 \times 10^{5} \mathrm{CFU} / \mathrm{mL}$ in $\mathrm{LB}$ and mixed with polymyxin B or LL-37 at indicated concentrations. After incubation at $37^{\circ} \mathrm{C}$ for $2.5 \mathrm{~h}$, the number of live bacteria was determined by plating and colony counts.

\subsection{SDS Susceptibility Assay}

Overnight bacterial cultures were subcultured into a fresh LB medium to an $\mathrm{OD}_{600}$ of approximately 0.8 . The bacteria were harvested by centrifugation and transferred to an M9 medium and grown to an $\mathrm{OD}_{600}$ of 1.0. The bacteria were collected by centrifugation and washed twice with the M9 medium. A total of $1 \times 10^{9} \mathrm{CFU} / \mathrm{mL}$ bacteria were treated with $3.5 \mathrm{mM}$ SDS in the M9 medium for $45 \mathrm{~min}$ at $30^{\circ} \mathrm{C}$. The number of live bacteria was determined by plating and colony counts.

\subsection{Ethidium Bromide Influx Assay}

Bacteria were grown in $\mathrm{LB}$ to an $\mathrm{OD}_{600}$ of 1.0. The bacteria were collected by centrifugation. For the polymyxin $B$ treatment experiment, the bacteria were resuspended in fresh LB, followed by incubation with polymyxin B at the concentration of $0.039 \mu \mathrm{g} / \mathrm{mL}$ $(0.125 \mathrm{MIC})$ or $0.078 \mu \mathrm{g} / \mathrm{mL}(0.25 \mathrm{MIC})$ for $2.5 \mathrm{~h}$ [38]. For the SDS treatment experiment, the bacteria were resuspended in M9 and incubated in the presence of $3.5 \mathrm{mM}$ SDS for $45 \mathrm{~min}$ [39]. Then ethidium bromide was added to a final concentration of $2 \mu \mathrm{g} / \mathrm{mL}$. After incubation at $37^{\circ} \mathrm{C}$ for $15 \mathrm{~min}$, the fluorescence of each sample (excitation at $530 \mathrm{~nm}$, emission at $600 \mathrm{~nm}$ ) was measured with a Luminoskan Ascent Luminometer (Varioskan Flash, Thermo Scientific, Waltham, MA, USA).

\subsection{Dansyl-Polymyxin B Binding Assay}

The dansyl-polymyxin B was synthesized as previously described [40]. Briefly, $40 \mathrm{mg}$

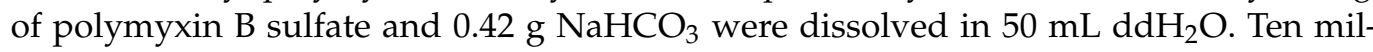
ligrams $(10 \mathrm{mg}$ ) of dansyl chloride was dissolved in $0.8 \mathrm{~mL}$ acetone. Then the two solutions were mixed and incubated at room temperature for $90 \mathrm{~min}$ in dark. A total of $12.5 \mathrm{~g}$ of G-25 Sephadex bead was added to a $2.5 \mathrm{~cm}$ diameter purification column, and treated with at least $100 \mathrm{~mL}$ balance buffer $\left(\mathrm{NaH}_{2} \mathrm{PO}_{4} 1.4196 \mathrm{~g}, \mathrm{NaCl} 8.4738 \mathrm{~g}\right.$, ddH $\mathrm{d}_{2} \mathrm{O} 1 \mathrm{~L}, \mathrm{pH}$ 7.10). The mixture was loaded into the column, eluted with the balance buffer. The eluent that appeared bright yellow under ultraviolet light was the dansyl-polymyxin B. The collected dansyl-polymyxin $B$ was then extracted with $1 / 2$ volume of butanol and dried by evaporation. The dansyl-polymyxin B powder was dissolved in N-2-hydroxyethylpiperazine-N-2ethane sulfonic acid (HEPES), $\mathrm{pH} 7.0$, and stored at $-20^{\circ} \mathrm{C}$.

Bacteria of the indicated strains were grown in $\mathrm{LB}$ to an $\mathrm{OD}_{600}$ of 1.0. The bacterial cells were collected by centrifugation and washed twice with normal saline $(0.9 \% \mathrm{NaCl})$. The bacterial cells were resuspended in normal saline to reach $1 \times 10^{9} \mathrm{CFU} / \mathrm{mL}$ and incubated with or without $0.26 \mu \mathrm{g} / \mathrm{mL}$ dansyl-polymyxin B for $5 \mathrm{~min}$ at $30{ }^{\circ} \mathrm{C}$ in dark. Then the bacteria were washed twice with normal saline and resuspended in $1 \mathrm{~mL}$ normal saline. A total of $150 \mu \mathrm{L}$ of the suspension was transferred into each well of a black 96-well microtiter plate (Nunc). The fluorescence (excitation at $340 \mathrm{~nm}$, emission at $485 \mathrm{~nm}$ ) was measured with a Luminoskan Ascent Luminometer (Varioskan Flash, Thermo Scientific, Waltham, MA, USA). The relative fluorescence intensity alter rate of dansyl-polymyxin B was calculated as $\left(100 \times\left(\mathrm{F}-\mathrm{F}_{0}\right) / \mathrm{F}_{0}\right) \%$. F: Fluorescence intensity of samples with dansylpolymyxin $B ; F_{0}$ : Fluorescence intensity of samples without dansyl-polymyxin $B$.

\subsection{Outer Membrane Permeability Assay}

The outer membrane permeability assay was performed as previously described [41,42]. Overnight cultures of indicated strains were transferred to fresh LB and grown to an $\mathrm{OD}_{600}$ of 1.0. Bacterial cells were washed twice with $5 \mathrm{mM}$ HEPES containing $5 \mathrm{mM}$ glucose ( $\mathrm{pH} 7.0$ ) and resuspended in the HEPES buffer to an $\mathrm{OD}_{600}$ of 0.5 , followed by incubation 
with $10 \mu \mathrm{M} \mathrm{NPN}$ at $25^{\circ} \mathrm{C}$ for $30 \mathrm{~min}$. Then the bacteria were incubated with or without $0.78 \mu \mathrm{g} / \mathrm{mL}$ polymyxin $\mathrm{B}$ at $37^{\circ} \mathrm{C}$ for another $30 \mathrm{~min}$. The fluorescence intensities (excitation wavelength: $350 \mathrm{~nm}$, emission wavelength: $420 \mathrm{~nm}$ ) were measured with a Luminoskan Ascent Luminometer (Varioskan Flash, Thermo Scientific, Waltham, MA, USA). The relative fluorescence intensity was calculated as $\left(100\left(\mathrm{~F}-\mathrm{F}_{0}\right) / \mathrm{F}_{0}\right) \%$. $\mathrm{F}$ and $\mathrm{F}_{0}$ represent fluorescence intensities of samples with polymyxin B and without polymyxin $\mathrm{B}$ treatment, respectively.

\subsection{Inner Membrane Integrity Assay}

The inner membrane integrity assay was performed as previously described $[43,44]$. Briefly, bacteria at an $\mathrm{OD}_{600}$ of 1.0 were washed twice with phosphate buffer saline (PBS, $\mathrm{pH}$ 7.2) and resuspended to an $\mathrm{OD}_{600}$ of 0.5 . The bacteria were incubated with $10 \mu \mathrm{M}$ PI at $25^{\circ} \mathrm{C}$ for $30 \mathrm{~min}$. Then the bacterial samples were incubated with or without $0.78 \mu \mathrm{g} / \mathrm{mL}$ polymyxin B at $37^{\circ} \mathrm{C}$ for $1 \mathrm{~h}$. The fluorescence values of the samples were detected under the conditions of excitation wavelength $535 \mathrm{~nm}$ and emission wavelength $615 \mathrm{~nm}$ with a Luminoskan Ascent luminometer (Varioskan Flash, Thermo Scientific, Waltham, MA, USA). The result of relative fluorescence intensity was calculated as $\left(100\left(\mathrm{~F}-\mathrm{F}_{0}\right) / \mathrm{F}_{0}\right) \%$. $\mathrm{F}$ and $\mathrm{F}_{0}$ represent fluorescence intensities of samples with polymyxin B and without polymyxin B treatment, respectively.

\subsection{Statistical Analysis}

All experiments were carried out at least in triplicate. Statistical significance was evaluated by the Prism software (Graphpad Software) via a one-way analysis of variance (ANOVA).

\section{Results}

\subsection{Identification of Genes Directly Regulated by PhoP in P. aeruginosa}

To identify genes directly regulated by the PhoP, we overexpressed a FLAG tagged PhoP in the wild-type PA14 and performed ChIP-Seq. The DNA binding loci and enrichment folds were listed in Table S1. The intergenic regions that were enriched more than 2-fold are shown in Table 1. Consistent with previous reports, the promoter regions of oprH, PA14_46900 and $a r n B$ were enriched by 17.2-, 15-, and 6.9-fold, respectively. In a previous study, the PhoP binding sequence was predicted as CGTTCAGNNNNNRTTCAG [32]. A multiple expression motifs for elicitation (MEME) analysis of our ChIP-Seq peak regions revealed the potential PhoP binding motif as G/ATTCAG (Figure 1A), which is similar to the repeated sequence in the previously predicted PhoP consensus binding sequence (underlined). The potential PhoP binding motif was found in the regions upstream of the open reading frames of PA14_46900, PA14_50740, PA14_50750, PA14_52340, and the operons of PA14_11970-PA14_11960 (within the open reading frame of PA14_11980) and PA14_52350-PA14_52370, as well as the regions between the $3^{\prime}$ ends of the coding regions of PA14_21870 and PA14_21860 (Figure 1B). Although the promoter region of pilY1 was enriched in the ChIP-Seq assay, no G/ATTCAG-like sequence was found upstream of the pilY1 coding region (Figure 1B).

To verify whether PhoP-PhoQ controls the expression of those genes, we performed quantitative real time PCR assays. Mutation of $p h o P$ and $p h o Q$ individually or simultaneously did not affect the expression level of pilY1, PA14_11980, PA14_21860 or PA14_21870 (Figure 1C). However, deletion of the $p h o Q$ gene increased the expression levels of PA14_11970, PA14_46900, PA14_50740, PA14_52340 and PA14_52350 (Figure 1C). Meanwhile, deletion of phoP or both phoP and $p h o Q$ reduced the expression of these genes (Figure 1C). In wild-type PA14, the expression of PA14_11970, PA14_46900, PA14_50740, PA14_52340, and PA14_52350 was induced by a low $\mathrm{Mg}^{2+}$ growth condition compared to the high $\mathrm{Mg}^{2+}$ condition [45], which was abolished by the deletion of phoP (Figure 1D). 
Table 1. Potential PhoP regulated genes identified via ChIP-seq.

\begin{tabular}{ccc}
\hline Genes & $\begin{array}{c}\text { Summits in PA14 } \\
\text { Chromosome }\end{array}$ & Fold Enrichment \\
\hline oprH & 4372078 & 17.23 \\
PA14_46900, PA14_46910 & 4177576 & 15.03 \\
arnB & 1578361 & 6.85 \\
PA14_50740, PA14_50750 & 4508762 & 6.24 \\
PA14_21860, PA14_21870 & 1900312 & 5.29 \\
PA14_52340, PA14_52350 & 4644776 & 4.87 \\
PA14_11970, PA14_11980 & 1035748 & 4.17 \\
pilY1 & 5372861 & 2.85 \\
\hline
\end{tabular}

To confirm the promoters of these genes are regulated by PhoP, we constructed transcriptional fusions between each of the promoters and a lacZ gene, resulting in P PA14_11970lacZ, P PA14_46900-lacZ, P PA14_50740-lacZ, P PA14_52340-lacZ and P PA14_52350-lacZ. The LacZ activities were decreased in the $\triangle p h o P$ and $\triangle p h o P \Delta p h o Q$ mutants, but increased in the $\Delta p h o Q$ mutant (Figure 2A-E). We then performed EMSA to verify the direct binding between PhoP and these promoters. Consistent with a previous report [32], the purified PhoP protein bond to the promoter region of PA14_46900 (Figure 2F). In addition, band shifts were observed with the promoter regions of, PA14_50740, PA14_11970-PA14_11980, and PA14_52340PA14_52350 (Figure 2F). In combination, these results suggested that the PhoP-PhoQ two component regulatory system directly controls the expression of PA14_46900, PA14_50740 as well as the operons of PA14_52350-PA14_52370 and PA14_11970-PA14_11960 in response to $\mathrm{Mg}^{2+}$ concentrations. Based on the conserved the domains and previous studies, the functions and the designated names of the PhoP-PhoQ regulated genes were listed in Table 2. 


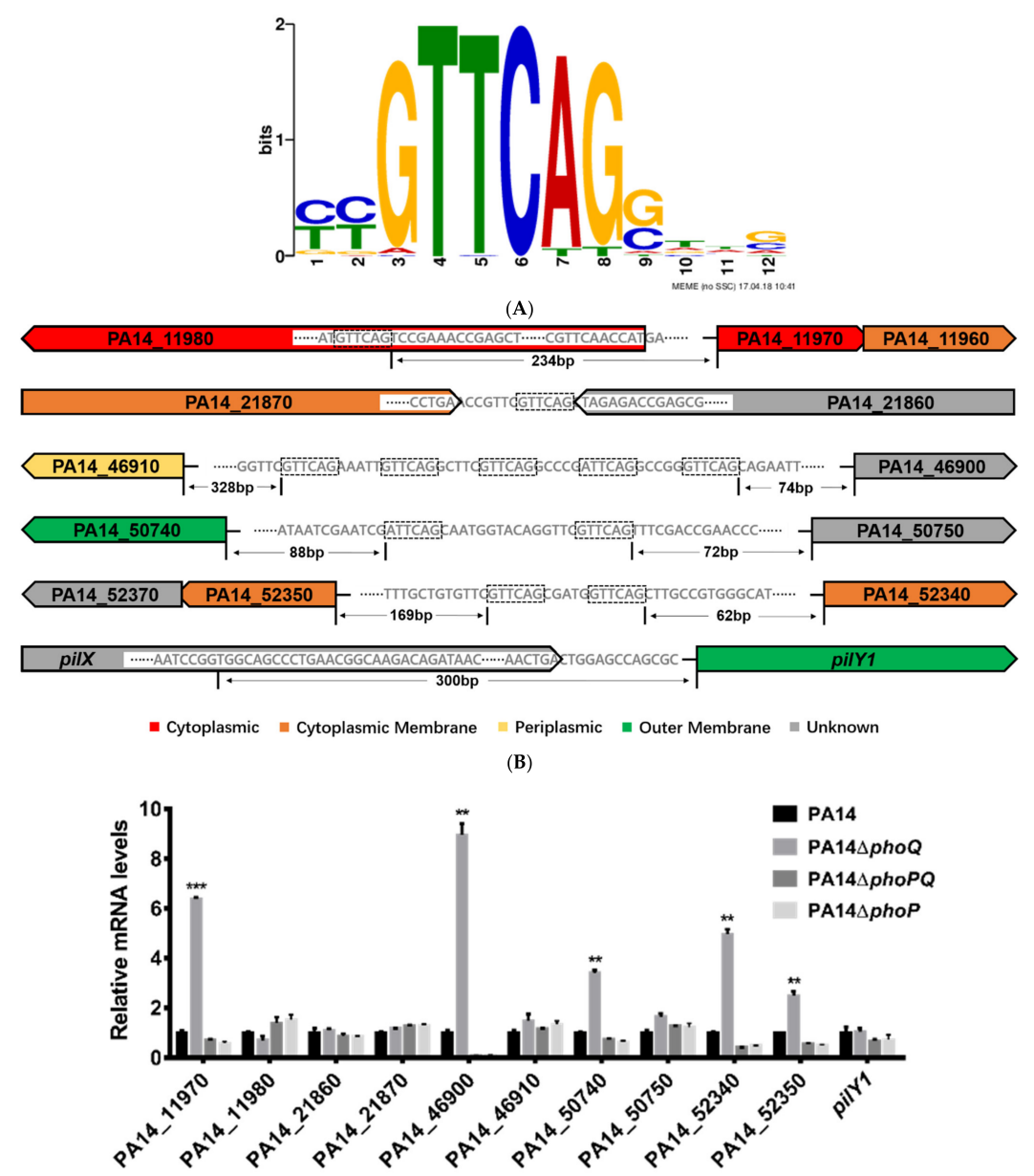

(C)

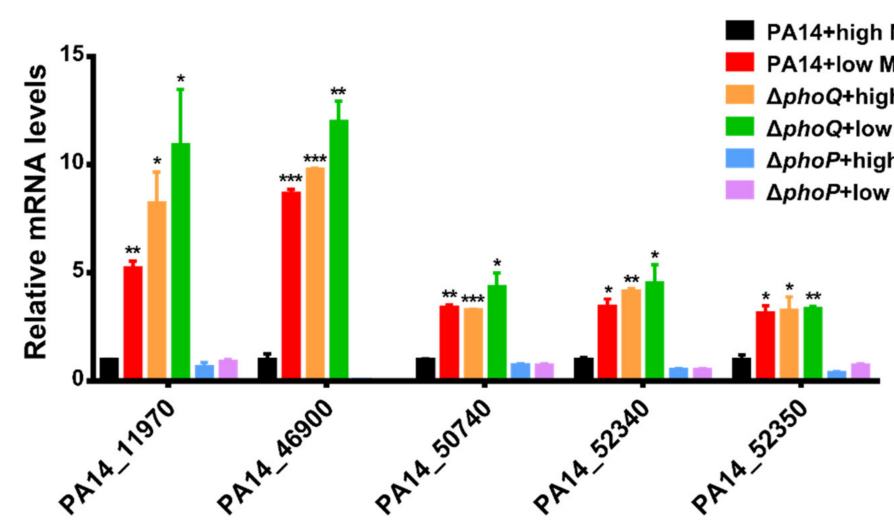

(D)

Figure 1. Genes controlled by the PhoP-PhoQ two-component regulatory system. (A) Potential PhoP binding motif was identified by MEME from the ChIP-seq peak regions. (B) Locations of the enriched peaks on the PA14 chromosome. The predicted $p h o P$ binding sequences are boxed. Colors of the genes were adopted from the Pseudomonas Genome Database (www.pseudomonas.com). (C) The wild-type PA14, $\Delta p h o P, \Delta p h o Q$, and $\Delta p h o P \Delta p h o Q$ mutants were grown to an $\mathrm{OD}_{600}$ of 1.0. The mRNA levels of the indicated genes were determined by quantitative real time PCR. (D) The wild-type PA14, $\Delta p h o P$, and $\triangle p h o Q$ mutants were grown to an $\mathrm{OD}_{600}$ of 1.0 in the $\mathrm{BM} 2$ medium with high $\mathrm{Mg}^{2+}(2 \mathrm{mM})$ and low $\mathrm{Mg}^{2+}$ $(2 \mu \mathrm{M})$. The mRNA levels of the indicated genes were determined by quantitative real time PCR. Data represents mean \pm standard deviation. ${ }^{*}, p<0.05 ;{ }^{* *}, p<0.01 ;{ }^{* * *}, p<0.001$ by Student's $t$-test. 


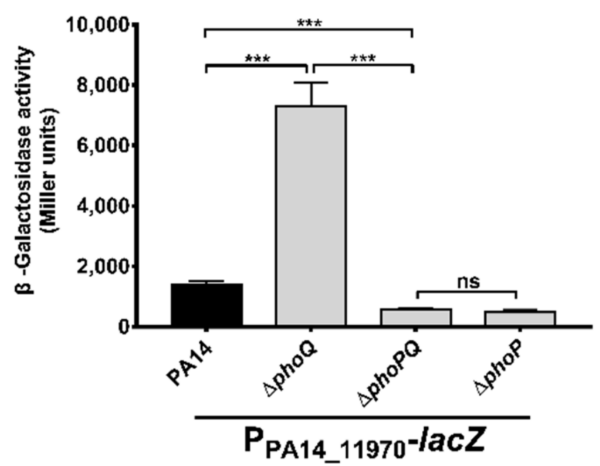

(A)

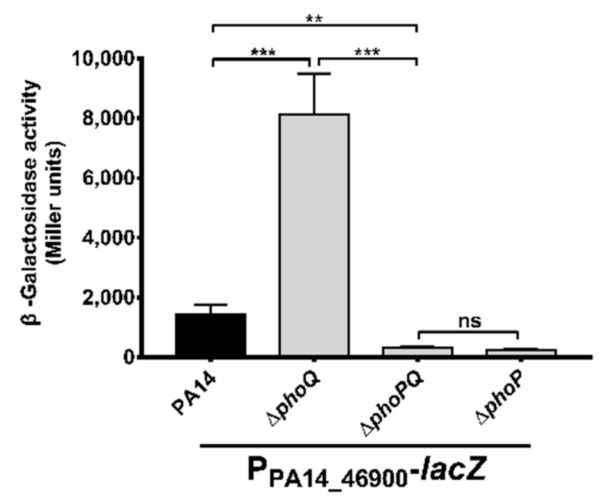

(B)

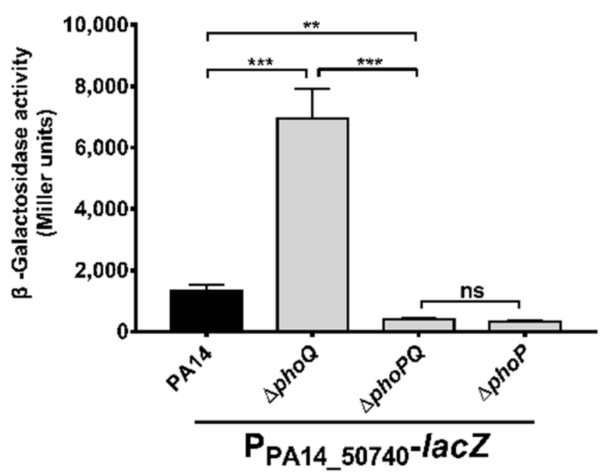

(C)

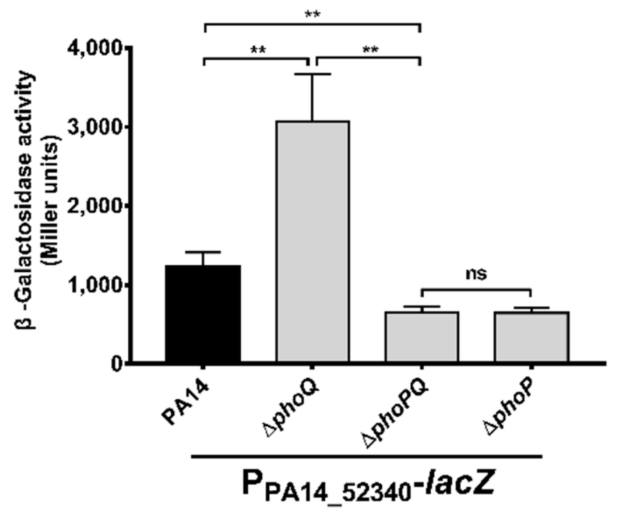

(D)

Figure 2. Cont. 


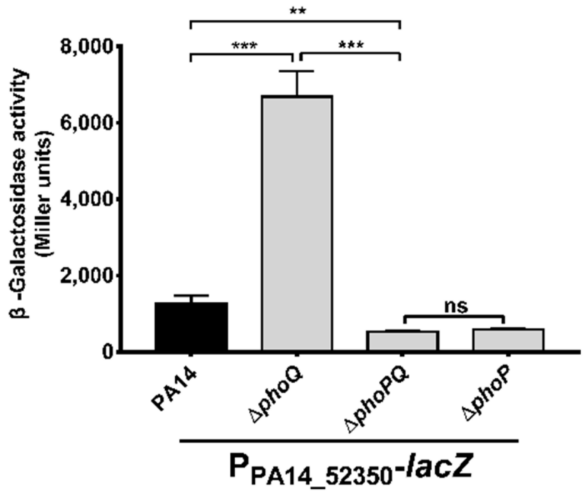

(E)
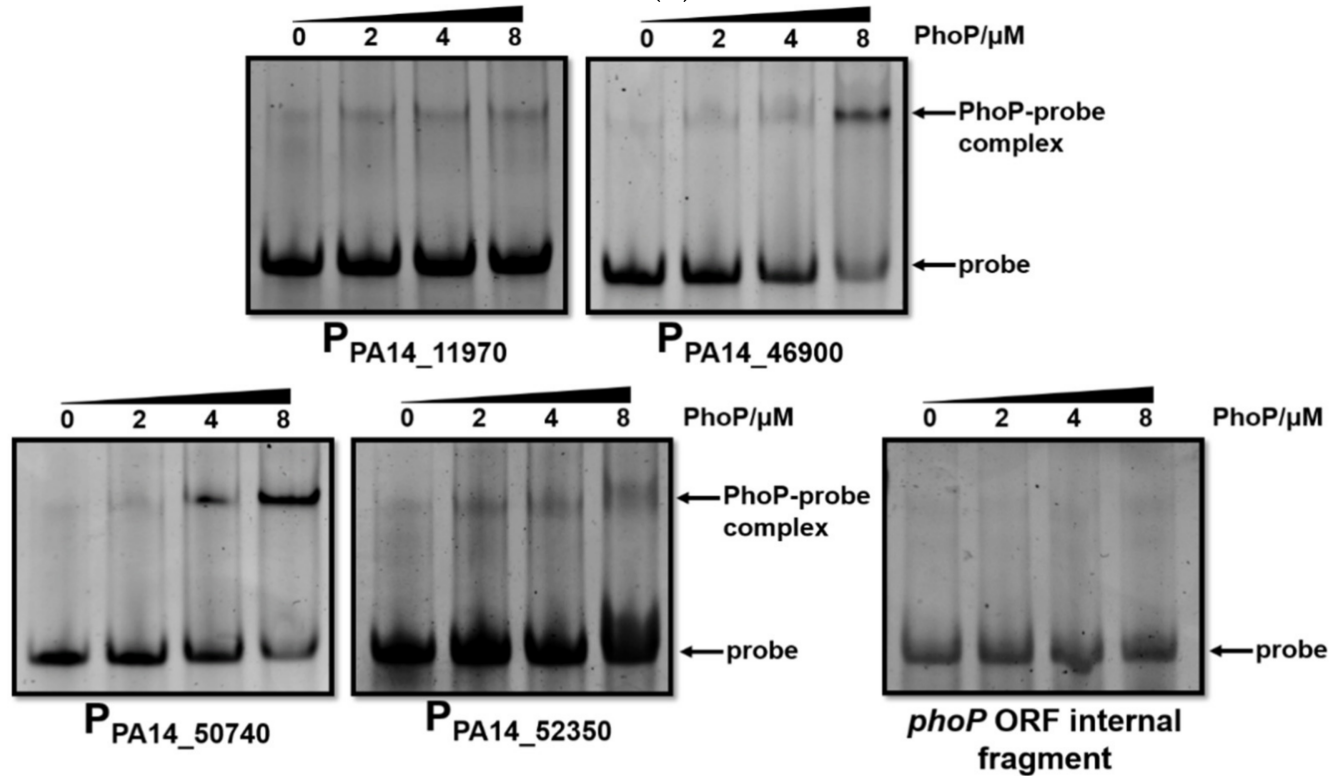

(F)

Figure 2. Promoters regulated by the PhoP-PhoQ two-component regulatory system. The transcriptional fusions of $\mathrm{P}_{\mathrm{PA} 14 \_11970-\text { lac } Z}$ (A), P PA14_46900-lacZ (B), P PA14_50740-lacZ (C), P PA14_52340-lacZ (D), and P PA14_52350-lacZ (E) were transferred into PA14 and the phoP, pho $Q$, and phoP-phoQ mutants. The bacteria were cultured in $\mathrm{LB}$ at $37^{\circ} \mathrm{C}$ to an $\mathrm{OD}_{600}$ of 1.0. The values (Miller units) are the means of three experiments. ns, not significant. ${ }^{* *}, p<0.01 ;{ }^{* * *}, p<0.001$, by Student's $t$-test. (F) Interactions between PhoP and its target DNAs were examined by EMSA. Purified $6 \times$ His-tagged PhoP was incubated with the promoter regions of the indicated genes (see Table S2). The internal fragment within the phoP coding region was used as a negative control. Arrows indicate the positions of unbound probe and PhoP-probe complex. 
Table 2. Functions of the identified PhoP regulated genes.

\begin{tabular}{|c|c|c|c|c|}
\hline PA14 Locus Tag & PAO1 Locus Tag & Functional Description & Product Name & Preliminary Phenotypic Analysis \\
\hline PA14_11960 & PA4011 & $\begin{array}{l}\text { PAP2 superfamily protein/DedA } \\
\text { family protein }\end{array}$ & $\begin{array}{l}\text { papP } P^{*}(\underline{\text { phosphatidic acid }} \\
\text { phosphatase in } \underline{P} \cdot a)\end{array}$ & \multirow[t]{2}{*}{$\begin{array}{l}\text { Upregulated by low concentrations of } \mathrm{Mg}^{2+}[32] \\
\text { Peptidoglycan recycling [46] }\end{array}$} \\
\hline PA14_11970 & PA4010 & 3-methyladenine DNA glycosylase & $m p l$ * & \\
\hline PA14_46900 & PA1343 & palmitoyltransferase & pagP & $\begin{array}{l}\text { (1) Directly regulated by PhoP-PhoQ [32] } \\
\text { (2) Transfers palmitate to lipid A [31] }\end{array}$ \\
\hline PA14_52340 & PA0921 & hypothetical protein & / & Directly regulated by PhoP-PhoQ [32] \\
\hline PA14_52350 & PA0920 & $\begin{array}{l}\text { alanyl-phosphatidylglycerol } \\
\text { synthase }\end{array}$ & $p p g S *$ (phosphatidylglycerol & $\begin{array}{l}\text { Involved in polymyxin E MIC and might altered bacterial membrane } \\
\text { potential (a conjecture) [50] }\end{array}$ \\
\hline
\end{tabular}


Previous studies demonstrated that, besides PhoP-PhoQ, the two-component regulatory systems PmrA-PmrB, BqsS-BqsR, ParS-ParR, and CprS-CprR are also involved in the regulation of the $\operatorname{arn} B C A D T E F$ operon $[29,30,51,52]$. We thus examined whether the four two-component regulatory systems control the expression of the genes listed in Table 2. Mutants of the individual genes were picked up from the PA14 transposon mutant library [53]. As shown in Figure S1, the expression levels of papP, $m p l$, pagP, slyB, PA14_52340, $p p g S$, and $p p g H$ were similar between the mutants and the wild-type PA14, indicating that the four regulatory systems might not control the expression of these genes.

\subsection{Roles of PhoP-PhoQ Regulated Genes in the Bacterial Tolerance to Polymyxin B}

A previous study revealed that pagP encodes for a lipid A palmitoyltransferase which transfers palmitate to LPS [31]. However, its role in the bacterial tolerance to polymyxin B was not known. $p p g S$ and $p p g H$, which encodes an alanyl-phosphatidylglycerol synthase and hydrolase, respectively, had been shown to contribute to lipid homeostasis in cell membrane [50]. The functions of the other genes as well as the genes in the same operons, namely slyB, PA14_52340, and mpl-papP remain to be studied.

To examine the roles of the PhoP-PhoQ regulated genes in the bacterial resistance to polymyxin B, we selected strains with mutations in each of the genes from the PA14 transposon insertion library [53]. The mutants displayed the same MIC of polymyxin $B$ as the wild-type PA14 (Table 3). We then examined their roles in the bacterial tolerance to polymyxin B. The strains of papP::Tn, mpl::Tn, pagP $:: \operatorname{Tn}, \operatorname{sly} B:: \operatorname{Tn}, p p g S:: T n$, and $p p g H::$ Tn displayed lower survival rates than that of the wild-type PA14, whereas the strains of PA14_11980::Tn and PA14_52340::Tn displayed similar survival rates as the wild-type strain (Figure 3A).

Table 3. Bacterial susceptibilities to polymyxin B.

\begin{tabular}{cc}
\hline Strain & MIC $(\mu \mathrm{g} / \mathrm{mL})$ \\
\hline PA14 & 0.3125 \\
$\Delta p h o P$ & 0.1563 \\
$\Delta p a p P:: T n$ & 0.3125 \\
$\Delta m p l:: T n$ & 0.3125 \\
$\Delta$ PA14_11980::Tn & 0.3125 \\
$\Delta p a g P:: T n$ & 0.3125 \\
$\Delta s l y B:: T n$ & 0.3125 \\
$\Delta$ PA14_52340::Tn & 0.3125 \\
$\Delta p p g S:: T n$ & 0.3125 \\
$\Delta p p g H:: T n$ & 0.3125 \\
$\Delta p a p P$ & 0.3125 \\
$\Delta m p l$ & 0.3125 \\
$\Delta p a g P$ & 0.3125 \\
$\Delta s l y B$ & 0.3125 \\
$\Delta p p g S$ & 0.3125 \\
$\Delta p p g H$ & 0.3125 \\
$\Delta 5^{\mathrm{a}}$ & 0.3125 \\
$\Delta 6^{\mathrm{b}}$ & 0.1563 \\
\hline
\end{tabular}

a $\Delta 5, \Delta p a p P \Delta m p l \Delta s l y B \Delta p p g S \Delta p p g H ;{ }^{\text {b }} \Delta 6$, deletion of $p a g P$ in $\Delta 5$. 


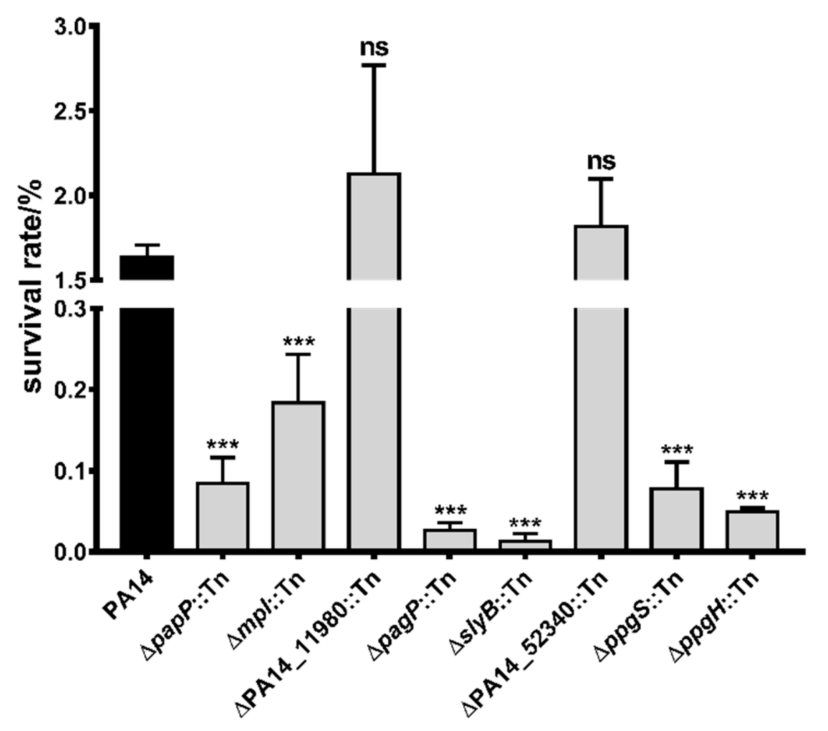

(A)

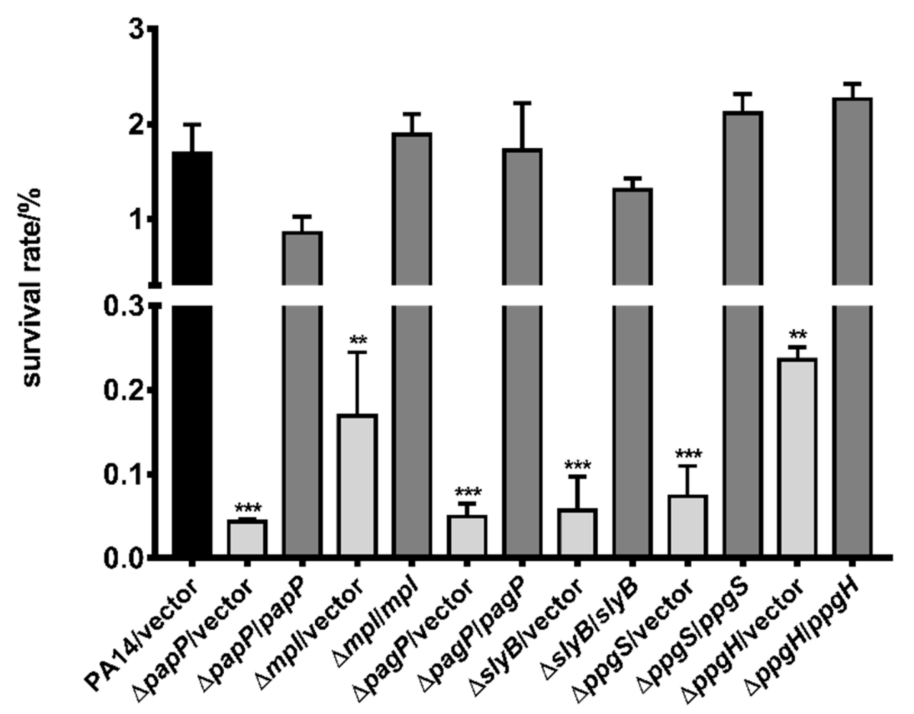

(B)

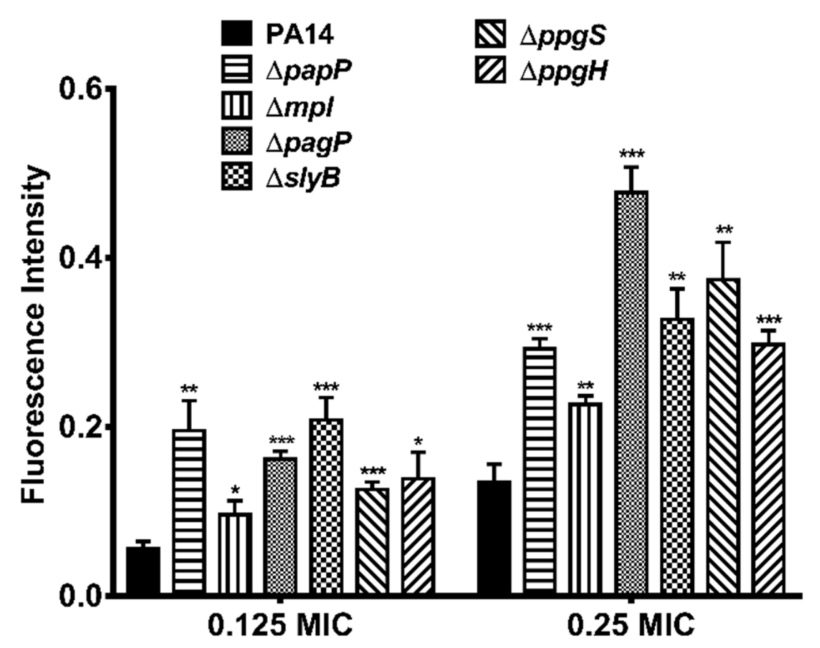

(C)

Figure 3. Cont. 


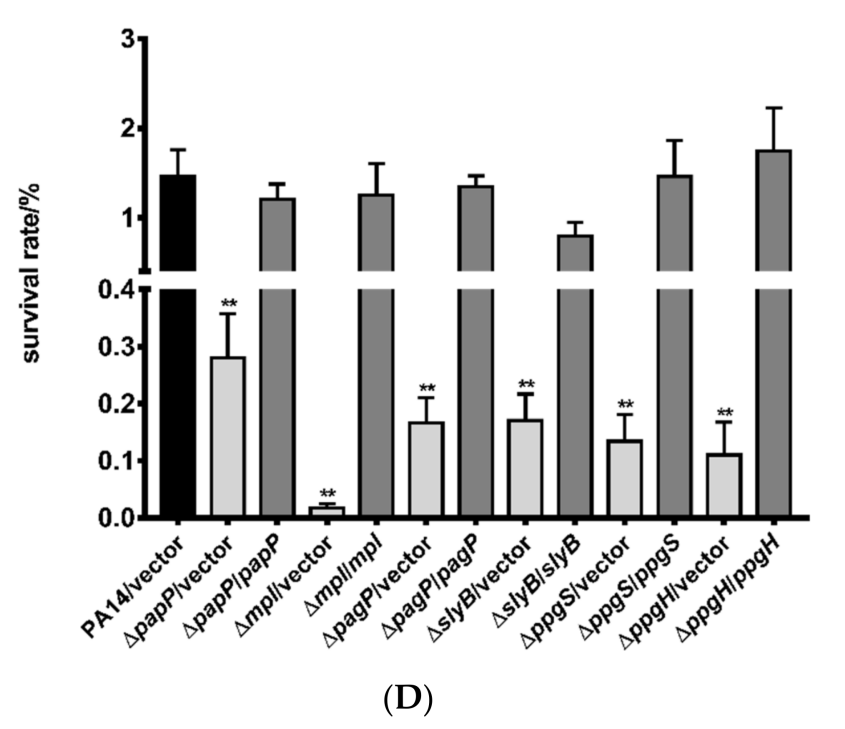

Figure 3. Roles of the PhoP regulated genes in the bacterial tolerance to polymyxin B and LL-37. Survival rates of the PA14 transposon insertion mutants (A), corresponding in-frame deletion mutants and respective complemented strains $(\mathbf{B})$ after polymyxin $B$ treatment. The strains were treated with polymyxin B $(0.78 \mu \mathrm{g} / \mathrm{mL})$ for $2.5 \mathrm{~h}$ at $37^{\circ} \mathrm{C}$. Error bars represent standard errors. ns, not significant. ${ }^{* *}, p<0.01, * * *, p<0.001$, compared to wild-type PA14 by Student's $t$ test. (C) The indicated strains were grown in $\mathrm{LB}$ to an $\mathrm{OD}_{600}$ of 1.0 and treated with $0.039 \mu \mathrm{g} / \mathrm{mL}(0.125 \mathrm{MIC})$ or $0.078 \mu \mathrm{g} / \mathrm{mL}$ (0.25 MIC) polymyxin B for $2.5 \mathrm{~h}$. Then the bacterial cells were stained with $2 \mu \mathrm{g} / \mathrm{mL}$ ethidium bromide, followed by fluorescence intensity determination. ${ }^{*}, p<0.05 ;{ }^{* *}, p<0.01 ;{ }^{* * *}, p<0.001$, compared to PA14 by Student's $t$-test. (D) The indicated strains were grown in LB to an $\mathrm{OD}_{600}$ of 1.0 and treated with $200 \mu \mathrm{g} / \mathrm{mL}$ LL-37 for $2.5 \mathrm{~h}$ at $37^{\circ} \mathrm{C}$. The bacterial survival rates were determined by serial dilution and plating. ${ }^{* *}, p<0.01$, compared to the wild-type PA14 by Student's $t$-test.

To further confirm the roles of these genes in the bacterial tolerance to polymyxin $B$, we constructed deletion mutants in wild-type PA14. Deletion of $p a p P, m p l, p a g P$, slyB, $p p g S$, and $p p g H$ reduced the bacterial survival rates after polymyxin $\mathrm{B}$ treatment. Complementation with the corresponding genes restored the survival rates (Figure 3B). Consistent with the results of survival rate, treatment with polymyxin $B$ resulted in higher ethidium bromide $(\mathrm{EtBr})$ influx in the mutants, indicating more severe membrane damage (Figure 3C). The human cationic antimicrobial peptide LL-37 kills bacteria via binding to LPS and subsequent damage of the cell membrane, which is similar to polymyxins [54]. Deletion of papP, $m p l$, pagP, slyB, ppgS, and ppgH also increased bacterial susceptibility to LL-37 (Figure 3D).

\subsection{Mechanisms of Polymyxin B Tolerance Mediated by the Identified Genes}

One of the major mechanisms of the bacterial tolerance to polymyxin $B$ is to reduce the binding between lipid A and polymyxin B [55]. We thus used a dansyl chloride labeled polymyxin B to measure the amount of surface associated polymyxin B [55]. Previous studies revealed a role of PagP in the palmitoylation of lipid A [56]. In agreement with its function, deletion of pagP increased the amount of the surface associated polymyxin $B$ (Figure 4A). However, mutation in the other genes did not affect the binding of polymyxin B to the cell (Figure $4 \mathrm{~A}$ ). 


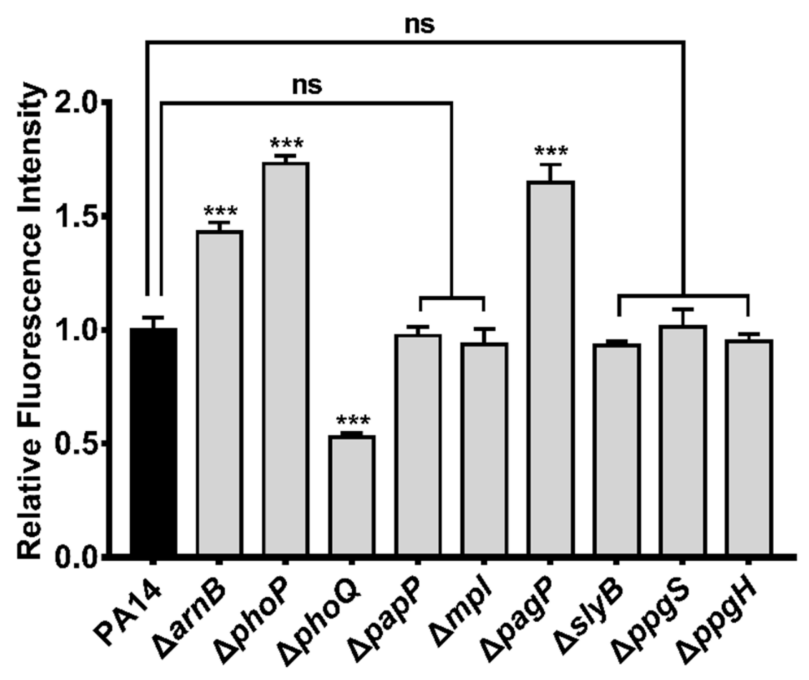

(A)

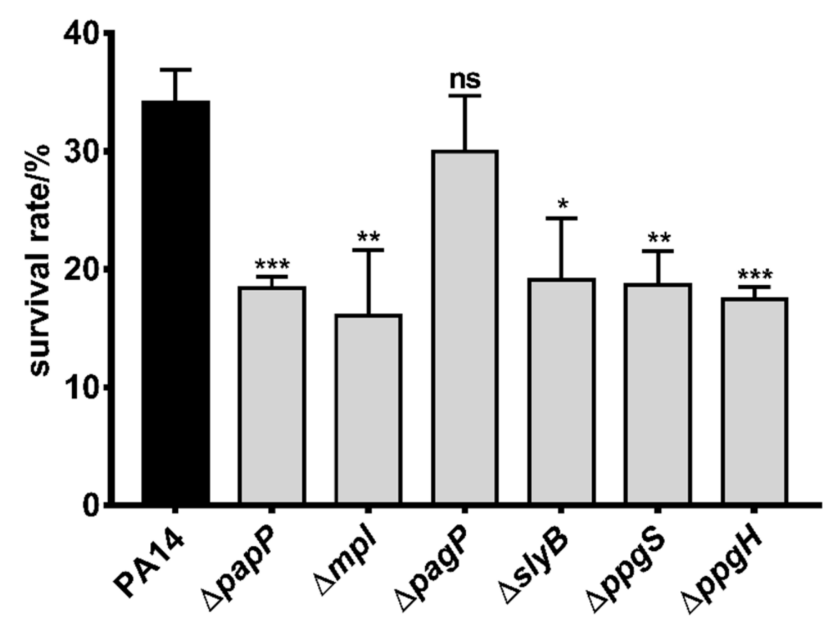

(B)

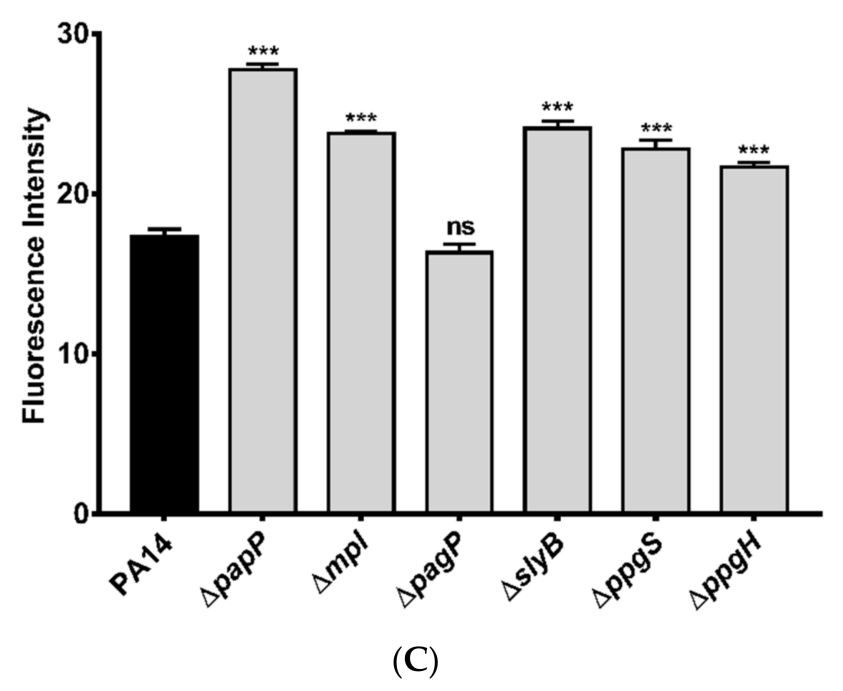

Figure 4. Cont. 


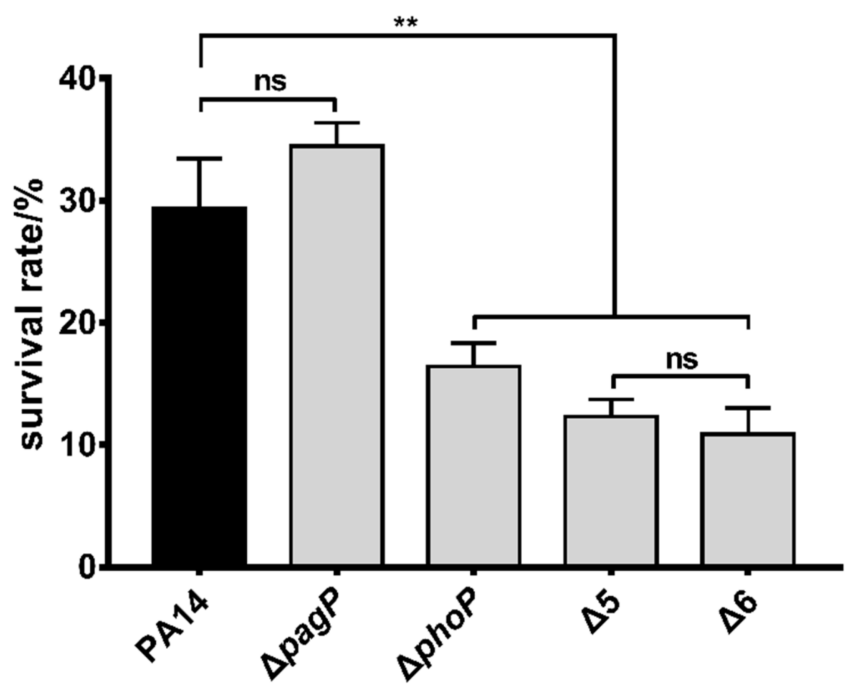

(D)

Figure 4. Roles of PhoP regulated genes in the bacterial tolerance to polymyxin B and SDS. (A) Dansylpolymyxin B binding assay. Wild-type PA14 and the indicated mutants were treated with dansylpolymyxin B $(0.26 \mu \mathrm{g} / \mathrm{mL})$ for $5 \mathrm{~min}$ in saline at $30^{\circ} \mathrm{C}$ in dark. The bacteria were washed twice with saline and the fluorescence intensities were determined with a luminometer. The data shown represents the results from three independent experiments. ns, not significant; ${ }^{* * *}, p<0.001$ compared to the wild-type PA14 by Student's $t$-test. $(\mathbf{B}, \mathbf{C})$ The indicated strains were grown to an $\mathrm{OD}_{600}$ of 1.0 in the M9 medium, followed by treatment with $3.5 \mathrm{mM}$ SDS at $37^{\circ} \mathrm{C}$ for $45 \mathrm{~min}$. The bacteria were washed once with M9. Then the bacteria were subjected to serial dilution and plating on LB agar for CFU enumeration (B) or staining with $2 \mu \mathrm{g} / \mathrm{mL}$ ethidium bromide and fluorescence intensity measurement $(\mathbf{C})$. Data shown represent results from three independent experiments. ns, not significant; ${ }^{*}, p<0.05 ;{ }^{* *}, p<0.01 ;{ }^{* * *}, p<0.001$, compared to the wild-type PA14 by Student's $t$-test. (D) Wild-type PA14 and the indicated mutants were grown in the M9 medium to an $\mathrm{OD}_{600}$ of 1.0. The bacteria were treated with $3.5 \mathrm{mM}$ SDS for $45 \mathrm{~min}$. The live bacteria numbers were determined by serial dilution and plating. ns, not significant; ${ }^{* *}, p<0.01$ by Student's $t$-test.

We then examined the roles of the genes in response to membrane damage. Treatment with SDS resulted in more cell death and EtBr influx in the strains of $\Delta p a p P, \Delta m p l, \Delta s l y B$, $\triangle p p g S$ and $\Delta p p g H$ (Figure $4 \mathrm{~B}, \mathrm{C}$ ). Simultaneous deletion of the five genes (designated as $\Delta 5$ ) further decreased the bacterial survival rate upon SDS treatment (Figure 4D). However, deletion of pagP in wild-type PA14 and the $\Delta 5$ mutant (designated as $\Delta 6$ ) did not reduce the bacterial resistance to SDS compared to the corresponding parental strains (Figure 4D), indicating that $p a p P, m p l, s l y B, p p g S$, and $p p g H$ are involved in bacterial response to membrane damage.

We next dissected the roles of the five genes in maintaining outer and inner membrane integrity by NPN and PI staining, respectively. After treatment with polymyxin B, the $\triangle p h o P$ and $\triangle p h o Q$ mutants displayed higher and lower NPN/PI stains than the wild-type PA14, respectively (Figure 5A,B), demonstrating an important role of the PhoP-PhoQ regulatory system in protecting the membranes against polymyxin $\mathrm{B}$. Deletion of papP or $s l y B$ increased the NPN staining whereas deletion of $m p l, p p g S$ and $p p g H$ did not affect the NPN staining (Figure 5A). SlyB is predicted to be a lipoprotein that localized on outer membrane [57]. It might inhibit the insertion of polymyxin B into the outer membrane or play a role in membrane repair [49]. PapP is predicted to localize in the inner membrane and contains a potential type 2 phosphatidic acid phosphatase domain $[57,58]$. It might be involved in the modification of outer membrane which contributes to bacterial tolerance to polymyxin B. 


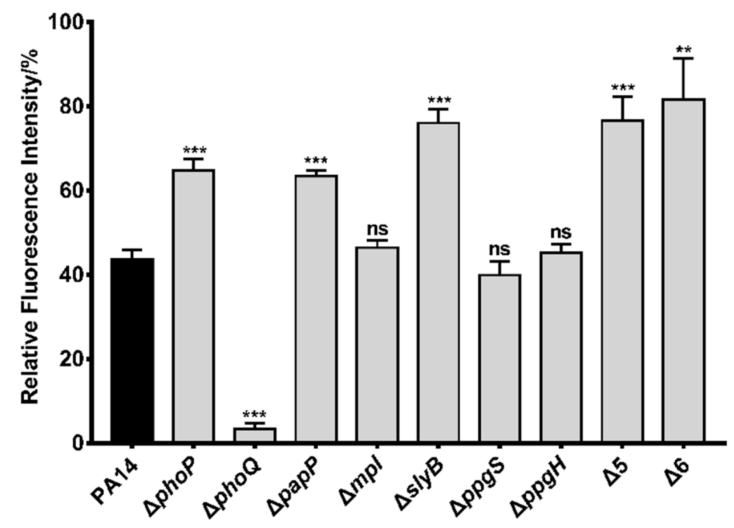

(A)

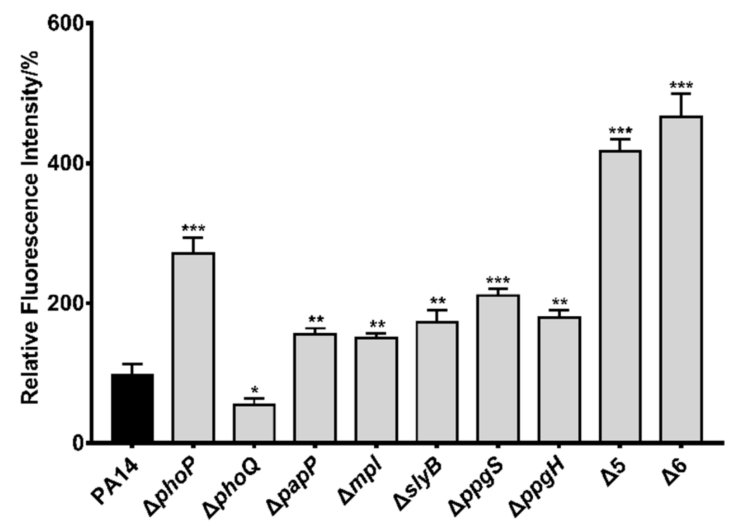

(B)

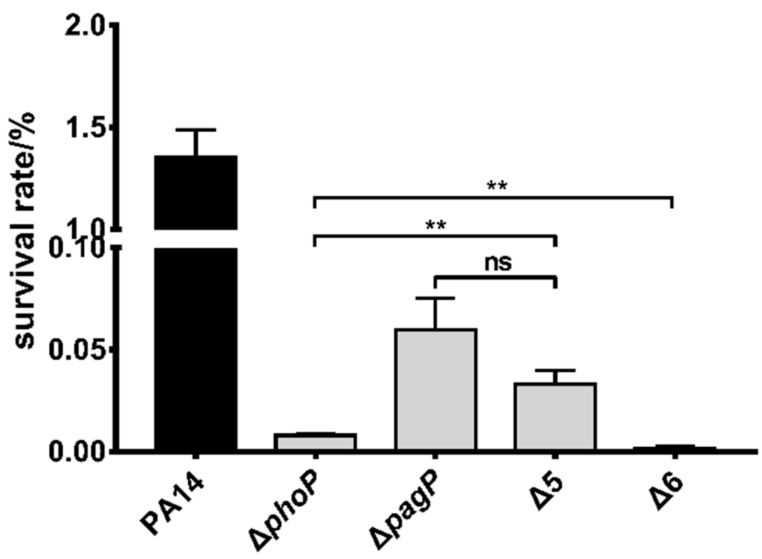

(C)

Figure 5. Roles of PhoP regulated genes in maintaining outer and inner membrane integrity. (A) Bacteria at an $\mathrm{OD}_{600}$ of 1.0 were collected and washed twice with $5 \mathrm{mM}$ HEPES containing $5 \mathrm{mM}$ glucose. The bacteria were resuspended in the HEPES buffer to an $\mathrm{OD}_{600}$ of 0.5 , followed by incubation with $10 \mu \mathrm{M} N P N$ at $25^{\circ} \mathrm{C}$ for $30 \mathrm{~min}$. Then the bacteria were incubated with or without $0.78 \mu \mathrm{g} / \mathrm{mL}$ polymyxin $\mathrm{B}$ at $37^{\circ} \mathrm{C}$ for $30 \mathrm{~min}$, followed by fluorescence measurement. (B) Bacteria at an $\mathrm{OD}_{600}$ of 1.0 were washed twice with PBS ( $\mathrm{pH} 7.2$ ) and resuspended in PBS to an $\mathrm{OD}_{600}$ of 0.5 . The bacteria were incubated with $10 \mu \mathrm{M}$ PI at $25^{\circ} \mathrm{C}$ for $30 \mathrm{~min}$. Then the bacterial samples were incubated with or without $0.78 \mu \mathrm{g} / \mathrm{mL}$ polymyxin $\mathrm{B}$ at $37^{\circ} \mathrm{C}$ for $1 \mathrm{~h}$, followed by fluorescence measurement. ns, not significant. ${ }^{*}, p<0.05 ;{ }^{* *}, p<0.01{ }^{* * *}, p<0.001$ compared to PA14 by Student's $t$-test (C) Wild-type PA14 and the indicated mutants were grown to an $\mathrm{OD}_{600}$ of 1.0. The bacteria were treated with $0.78 \mu \mathrm{g} / \mathrm{mL}$ polymyxin B for $2.5 \mathrm{~h}$ at $37^{\circ} \mathrm{C}$. The live bacteria numbers were determined by serial dilution and plating. ns, not significant; ${ }^{* *}, p<0.01$, by Student's $t$-test. 
Meanwhile, deletion of each of the five genes increased PI staining after polymyxin B treatment (Figure 5B). Considering the roles of PapP and SlyB in reducing the outer membrane damage, the increased PI staining might be due to higher amount of polymyxin $\mathrm{B}$ that crossed the outer membrane. Since mutation of $m p l, p p g S$, or $p p g H$ did not affect the polymyxin B triggered outer membrane damage, the higher PI staining indicates that these genes might be involved in maintaining the inner membrane integrity. Mpl contains a potential methylpurine-DNA glycosylase domain and is predicted to localize in cytoplasm [57,58]. However, its physiological role remains unknown. PpgS and PpgH are inner membrane proteins involved in the modification of the phosphatidylglycerol in cell membrane, which might reduce the insertion of polymyxin B into the inner membrane.

We then determined the cumulative effect of the PhoP regulated genes in bacterial resistance to polymyxin B. The $\Delta 5$ mutant displayed the same MIC of polymyxin B as the wild-type strain, whereas the $\Delta 6$ and the $\Delta p h o P$ mutants displayed lower MICs in LB (Table 3) or CA-MHB medium (Table S4). The survival rates of the $\Delta 5$ and $\Delta 6$ mutants were lower than that of the wild-type strain following polymyxin B treatment (Figure 5C). Compared to the $\triangle p h o P$ mutant, the $\Delta 6$ mutant displayed a 4.7 -fold lower survival rate (Figure 5C). In combination, these results indicate that $p a p P, m p l$, slyB, $p p g S$, and $p p g H$ contribute to bacterial resistance to polymyxin $\mathrm{B}$ by maintaining membrane integrity while pagP reduces the binding of polymyxin $B$ to the bacterial LPS.

\section{Discussion}

In this study, we identified novel PhoP regulated genes by ChIP-Seq, including papP (PA14_11960), $m p l$ (PA14_11970), slyB (PA14_50740),ppgS (PA14_52350), and ppgH (PA14_52370), and demonstrated that these genes contribute to the bacterial tolerance to polymyxin $B$.

A previous study revealed that mutation of $p h o Q$ attenuates the bacterial virulence in a murine bacteremia infection model which is due to the upregulation of oprH that serves as a binding target of the complement component $C 3$ [59]. In addition, mutation of $p h o Q$ reduces the bacterial twitching motility, biofilm formation, cytotoxicity as well as virulence in a lettuce leaf and a chronic rat lung infection model [34]. Microarray analyses demonstrated that mutation of $p h o Q$ altered the expression of 474 genes [34]. In addition to the arnBCADTEF and $p m r A B$ operons, mutation of $p h o Q$ resulted in upregulation of genes involved in alginate, Pseudomonas quinolone signal (PQS) and pyoverdine synthesis as well as $\operatorname{sly} B$ [34].

pag $P$ encodes a palmitoyltransferase that is regulated by PhoP-PhoQ and contributes to the palmitoylation of lipid $A$ and the bacterial resistance to a synthetic cationic antimicrobial peptide C18G [31]. However, mutation of pagP in a $\triangle p h o Q$ mutant did not affect the bacterial resistance to polymyxin $B$ in colistin agar dilution and polymyxin B plate assays [31]. We suspect that the overexpression of the arnBCADTEF operon in the $\triangle p h o \mathrm{Q}$ mutant lead to a high-level L-Ara4N addition to lipid A, which might compensate for the loss of the palmitoylation. Here we found that mutation of pagP in wild-type PA14 decreased the bacterial survival rate in a polymyxin killing assay in liquid LB. However, simultaneous mutation of $p a g P$ and $a r n B$ resulted in a similar survival rate as the $p a g P$ or $a r n B$ mutant (Figure S2), indicating a possible redundancy of the modifications. Further studies are required to examine whether the palmitoylation of lipid A interfere with the addition of Ara4N, and vice versa.

SlyB is an outer membrane lipoprotein that has been shown to be involved in the stabilization of the outer membrane in E. coli and S. enterica [60]. A study in Burkholderia multivorans demonstrated that mutation of slyB impairs the bacterial growth in presence of EDTA, SDS or the iron (III) chelator ethylenediaminedi (o-hydroxyphenylacetic) acid (EDDHA) [49]. In P. aeruginosa, the expression of $s l y B$ has been shown to be regulated by $\mathrm{Alg} \mathrm{U}$, an alternative sigma factor that response to periplasmic stresses [61,62]. Here we found that SlyB contributes to the bacterial survival under polymyxin B and SDS treatment. The NPN staining assay revealed a role of SlyB in maintaining outer membrane 
integrity in response to polymyxin B. These results indicate a conserved role of SlyB in maintaining outer membrane integrity. However, the functional mechanism of SlyB remains to be elucidated.

PpgS and PpgH are localized in the cell membrane and function as alanyl-phosphatidylgly cerol synthase and alanyl-phosphatidylglycerol hydrolase, respectively [63-65]. The two enzymes are involved in the homeostasis of aminoacylation of the negatively charged headgroup of phosphatidylglycerol (PG), which affects the membrane surface charge, morphology, fluidity and contributes to maintaining the integrity of the cytoplasm membrane in response to environmental stresses [63,65]. Mutation of $p p g \mathrm{H}$ reduced the bacterial resistance to $\mathrm{Cr}^{3+}$, the cationic peptide protamine, the $\beta$-lactam antibiotic cefsulodin and an osmolality stress (625 mM sodium lactate) [63], and mutation of $p p g S$ reduced the bacterial resistance to a variety of antibiotics including ampicillin, cefsulodin, daptomycin, and polymyxins [65]. Through the NPN and PI staining assays, we indeed found that PpgS and PpgH contribute to inner, but not outer, membrane integrity following polymyxin B treatment, indicating an important role of the homeostasis of the aminoacylation of PG in the bacterial resistance to polymyxin $\mathrm{B}$.

PapP and mpl contain a phosphatidic acid phosphatase type 2/haloperoxidase and a methylpurine-DNA glycosylase domain, respectively [58]. However, further studies are needed to understand how the two proteins contribute to membrane integrity in response to polymyxin B. The PhoP-PhoQ mediated regulatory pathways and bacterial polymyxin resistance mechanisms was summarized in Figure 6.

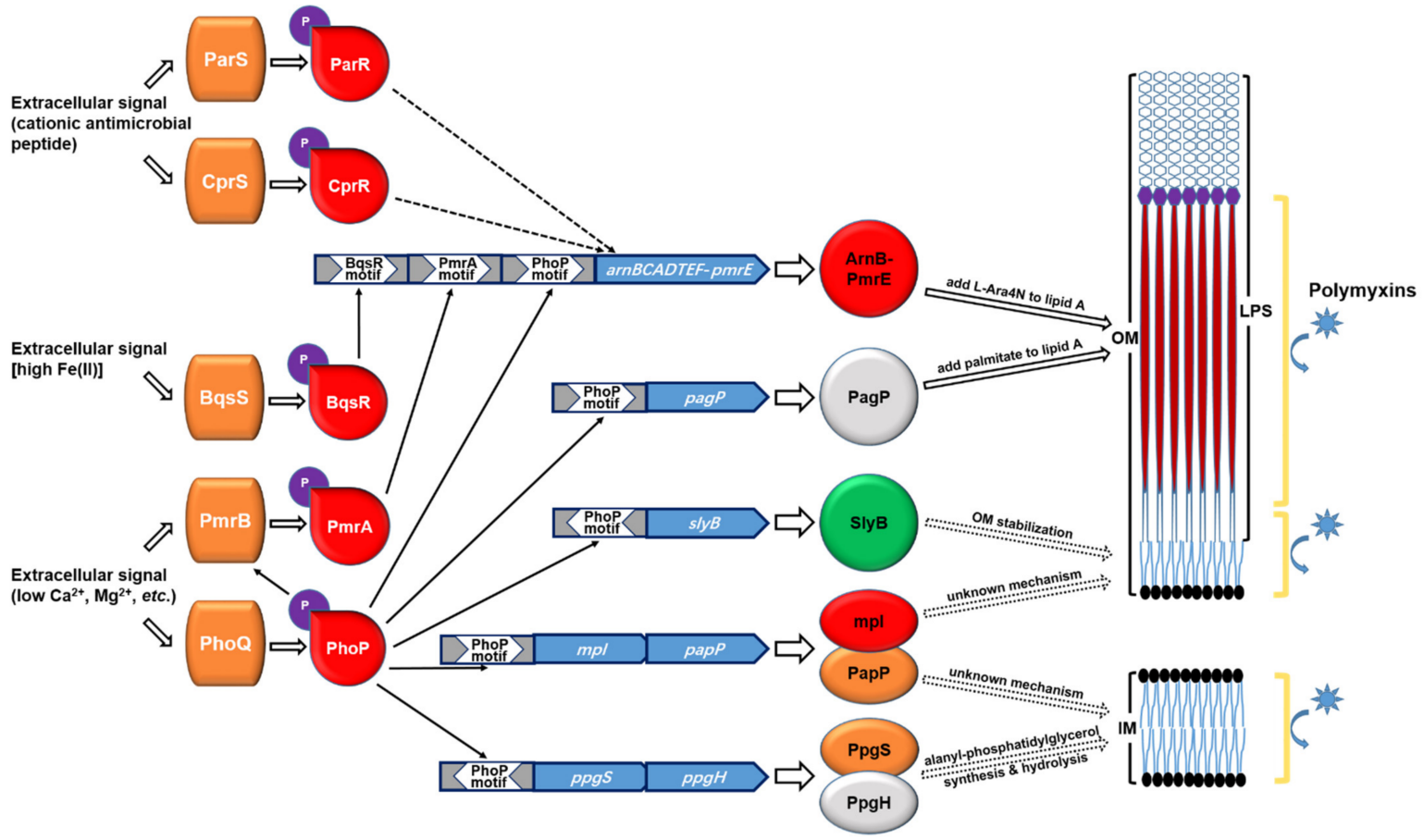

Figure 6. Schematic diagrams of PhoP-PhoQ regulated genes in the bacterial resistance to polymyxin B. The two-component regulatory systems PhoP-PhoQ and PmrA-PmrB are activated by depletion of divalent cations. Phosphorylated PmrA activates the transcription of arnBCADTEF-pmrE operon that contributes to bacterial resistance to polymyxins by adding L-Ara4N to lipid A (26). The two-component regulatory systems ParS-ParR and CprS-CprR activate expression of the arnBCADTEF-pmrE operon in response to cationic antimicrobial peptides [29]. Another two-component regulatory system BqsS-BqsR activates the expression of the arnBCADTEF-pmrE operon in response to Fe(II) [30]. Phosphorylated PhoP activates the expression of $p m r A-p m r B$ and the arnBCADTEF-pmrE operon as well as pagP, mpl-papP, slyB, and $p p g S-p p g H$. The $p a g P$ reduces the affinity between LPS and polymyxins through addition of palmitate to lipid A. The pap $P$ and $s l y B$ protect bacterial outer membrane integrity. The $m p l$ and $p p g S-p p g H$ are involved in maintaining inner membrane integrity in response to polymyxins. Colors of the genes were adopted from the Pseudomonas Genome Database (www.pseudomonas. com). 
In combination, our results reveal that the PhoP-PhoQ two-component regulatory system contributes to bacterial tolerance to polymyxin $\mathrm{B}$ by directly regulating genes involved in LPS modification and membrane integrity maintenance. These genes may also be involved in the bacterial response to environmental stresses such as cation depletion and host antimicrobial substances, which deserves further investigation.

Supplementary Materials: The following are available online at https:/ /www.mdpi.com/2076-260 7/9/2/344/s1; Figure S1. Relative mRNA levels of PhoP-PhoQ-related target genes in other TCS mutants; Figure S2. Roles of PA14_46900 and arnB in the bacterial tolerance to polymyxin B; Table S1. Potential PhoP binding sites identified by ChIP-Seq; Table S2. Bacterial strains and plasmids used in this study; Table S3. Primers used in this study; Table S4. Bacterial susceptibilities to polymyxin B in CA-MHB.

Author Contributions: Conceptualization: B.Y. and W.W.; methodology: B.Y.; software: B.Y.; investigation: B.Y., C.L., X.P., W.F., Z.F.; resources: X.P.; data curation: C.L..; writing-original draft preparation: B.Y. and W.W.; writing-review and editing: B.Y., Y.J., F.B., Z.C., W.W.; supervision: W.W.; funding acquisition: Y.J., F.B., Z.C., W.W. All authors have read and agreed to the published version of the manuscript.

Funding: This research was funded by National Key Research and Development Project of China (2017YFE0125600), National Science Foundation of China (31970179, 31970680, 31900115, and 31870130), and the Tianjin Municipal Science and Technology Commission (19JCYBJC24700). The funders had no role in study design, data collection and interpretation, or the decision to submit the work for publication.

Institutional Review Board Statement: Not applicable.

Informed Consent Statement: Not applicable.

Data Availability Statement: The data presented in this study are available on request from the corresponding author.

Conflicts of Interest: The authors declare no conflict of interest.

\section{References}

1. Zanin, M.; Baviskar, P.; Webster, R.; Webby, R. The interaction between respiratory pathogens and mucus. Cell Host Microbe 2016, 19, 159-168. [CrossRef]

2. Anantharajah, A.; Mingeot-Leclercq, M.P.; Bambeke, V.F. Targeting the type three secretion system in Pseudomonas aeruginosa. Trends Pharmacol. Sci. 2016, 37, 734-749. [CrossRef] [PubMed]

3. Lister, P.D.; Wolter, D.J.; Hanson, N.D. Antibacterial-resistant Pseudomonas aeruginosa: Clinical impact and complex regulation of chromosomally encoded resistance mechanisms. Clin. Microbiol. Rev. 2009, 22, 582-610. [CrossRef]

4. Zhao, S.; Adamiak, J.W.; Bonifay, V.; Mehla, J.; Zgurskaya, H.I.; Tan, D.S. Defining new chemical space for drug penetration into Gram-negative bacteria. Nat. Chem. Biol. 2020, 12, 1293-1302. [CrossRef] [PubMed]

5. Hulen, C.; Racine, P.J.; Chevalier, S.; Feuilloley, M.; Lomri, N.E. Identification of the PA1113 gene product as an ABC transporter involved in the uptake of carbenicillin in Pseudomonas aeruginosa PAO1. Antibiotics 2020, 9, 596. [CrossRef]

6. Azimi, L.; Fallah, F.; Karimi, A.; Shirdoust, M.; Azimi, T.; Sedighi, I.; Rahbar, M.; Armin, S. Survey of various carbapenem-resistant mechanisms of Acinetobacter baumannii and Pseudomonas aeruginosa isolated from clinical samples in Iran. Iran. J. Basic Med. Sci. 2020, 23, 1396-1400. [CrossRef] [PubMed]

7. Moradali, M.F.; Ghods, S.; Rehm, B.H.A. Pseudomonas aeruginosa lifestyle: A paradigm for adaptation, survival, and persistence. Front. Cell. Infect. Microbiol. 2017, 7, 39. [CrossRef]

8. Puja, H.; Bolard, A.; Noguès, A.; Plésiat, P.; Jeannot, K. The efflux pump MexXY/OprM contributes to the tolerance and acquired resistance of Pseudomonas aeruginosa to colistin. Antimicrob. Agents Chemother. 2020, 64, e02033-19. [CrossRef]

9. Hao, G.; Chen, A.I.; Liu, M.; Zhou, H.; Egan, M.; Yang, X.; Kan, B.; Wang, H.; Goulian, M.; Zhu, J. Colistin-resistance-mediated bacterial surface modification sensitizes phage infection. Antimicrob. Agents Chemother. 2019, 63, e01609-19. [CrossRef]

10. Genteluci, G.L.; de Souza, P.A.; Gomes, D.B.C.; Sousa, V.S.; de Souza, M.J.; Abib, J.R.L.; de Castro, E.A.R.; Rangel, K.; Bôas, M.H.S.V. Polymyxin B heteroresistance and adaptive resistance in multidrug- and extremely drug-resistant Acinetobacter baumannii. Curr. Microbiol. 2020, 77, 2300-2306. [CrossRef]

11. Soon, R.L.; Velkov, T.; Chiu, F.; Thompson, P.E.; Kancharla, R.; Roberts, K.; Larson, I.; Nation, R.L.; Li, J. Design, synthesis, and evaluation of a new fluorescent probe for measuring polymyxin-lipopolysaccharide binding interactions. Anal. Biochem. 2011, 409, 273-283. [CrossRef] [PubMed]

12. Domingues, M.M.; Inácio, R.G.; Raimundo, J.M.; Martins, M.; Castanho, M.A.R.B.; Santos, N.C. Biophysical characterization of polymyxin B interaction with LPS aggregates and membrane model systems. Biopolymers 2012, 98, 338-344. [CrossRef] [PubMed] 
13. Chen, S.; Shao, X.; Xiao, X.; Dai, Y.; Wang, Y.; Xie, J.; Jiang, W.; Sun, Y.; Cong, Z.; Qiao, Z.; et al. Host defense peptide mimicking peptide polymer exerting fast, broad spectrum, and potent activities toward clinically isolated multidrug resistant bacteria. ACS Infect. Dis. 2020, 6, 479-488. [CrossRef] [PubMed]

14. Velkov, T.; Deris, Z.Z.; Huang, J.X.; Azad, M.A.K.; Butler, M.; Sivanesan, S.; Kaminskas, L.M.; Dong, Y.; Boyd, B.; Baker, M.A.; et al. Surface changes and polymyxin interactions with a resistant strain of Klebsiella pneumoniae. Innate Immun. 2014, $20,350-363$. [CrossRef] [PubMed]

15. Velkov, T.; Soon, R.L.; Chong, P.L.; Huang, J.X.; Cooper, M.A.; Azad, M.A.K.; Baker, M.A.; Thompson, P.E.; Roberts, K.; Nation, R.L.; et al. Molecular basis for the increased polymyxin susceptibility of Klebsiella pneumoniae strains with under-acylated lipid A. Innate Immun. 2013, 19, 265-277. [CrossRef] [PubMed]

16. Krzyzanski, W.; Rao, G.G. Multi-scale model of drug induced adaptive resistance of Gram-negative bacteria to polymyxin B. PLoS ONE 2017, 12, e0171834. [CrossRef]

17. Trimble, M.J.; Mlynárčik, P.; Kolář, M.; Hancock, R.E.W. Polymyxin: Alternative mechanisms of action and resistance. Cold Spring Harb. Perspect. Med. 2016, 6, a025288. [CrossRef]

18. Macfarlane, E.L.A.; Kwasnicka, A.; Hancock, R.E.W. Role of Pseudomonas aeruginosa PhoP-phoQ in resistance to antimicrobial cationic peptides and aminoglycosides. Microbiology 2000, 146, 2543-2554. [CrossRef]

19. Macfarlane, E.L.A.; Kwasnicka, A.; Ochs, M.M.; Hancock, R.E.W. PhoP \pm PhoQ homologues in Pseudomonas aeruginosa regulate expression of the outer membrane protein OprH and polymyxin B resistance. Mol. Microbiol. 1999, 34, 305-316. [CrossRef]

20. Lesley, J.A.; Waldburger, C.D. Comparison of the Pseudomonas aeruginosa and Escherichia coli PhoQ sensor domains: Evidence for distinct mechanisms of signal detection. J. Biol. Chem. 2001, 276, 30827-30833. [CrossRef] [PubMed]

21. Brinkman, F.S.; Macfarlane, E.L.; Warrener, P.; Hancock, R.E.W. Evolutionary relationships among virulence-associated histidine kinases. Infect. Immun. 2001, 69, 5207-5211. [CrossRef]

22. Bell, A.; Bains, M.; Hancock, R.E.W. Pseudomonas aeruginosa outer membrane protein OprH: Expression from the cloned gene and function in EDTA and gentamicin resistance. J. Bacteriol. 1991, 173, 6657-6664. [CrossRef] [PubMed]

23. Conrad, R.S.; Galanos, C. Fatty acid alterations and polymyxin B binding by lipopolysaccharides from Pseudomonas aeruginosa adapted to polymyxin B resistance. Antimicrob. Agents Chemother. 1989, 33, 1724-1728. [CrossRef] [PubMed]

24. Guo, L.; Lim, K.B.; Gunn, J.S.; Bainbridge, B.; Darveau, R.P.; Hackett, M.; Miller, S.I. Regulation of lipid A modifications by Salmonella typhimurium virulence genes phoP-phoQ. Science 1997, 276, 250-253. [CrossRef] [PubMed]

25. Landman, D.; Bratu, S.; Alam, M.; Quale, J. Citywide emergence of Pseudomonas aeruginosa strains with reduced susceptibility to polymyxin B. J. Antimicrob. Chemother. 2005, 55, 954-957. [CrossRef]

26. Lee, M.; Sousa, M.C. Structural basis for substrate specificity in ArnB. A key enzyme in the polymyxin resistance pathway of Gram-negative bacteria. Biochemistry 2014, 53, 796-805. [CrossRef]

27. Miller, A.K.; Brannon, M.K.; Stevens, L.; Johansen, H.K.; Selgrade, S.E.; Miller, S.I.; Høiby, N.; Moskowitz, S.M. PhoQ mutations promote lipid A modification and polymyxin resistance of Pseudomonas aeruginosa found in colistin-treated cystic fibrosis patients. Antimicrob. Agents Chemother. 2011, 55, 5761-5769. [CrossRef] [PubMed]

28. Schurek, K.N.; Sampaio, J.L.M.; Kiffer, C.R.V.; Sinto, S.; Mendes, C.M.F.; Hancock, R.E.W. Involvement of pmrAB and phoPQ in polymyxin B adaptation and inducible resistance in non-cystic fibrosis clinical isolates of Pseudomonas aeruginosa. Antimicrob. Agents Chemother. 2009, 53, 4345-4351. [CrossRef]

29. Lee, J.Y.; Chung, E.S.; Na, I.N.; Kim, H.; Shin, D.; Ko, K.S. Development of colistin resistance in pmrA-, phoP-, parR- and cprR-inactivated mutants of Pseudomonas aeruginosa. J. Antimicrob. Chemother. 2014, 69, 2966-2971. [CrossRef]

30. Kreamer, N.N.K.; Wilks, J.C.; Marlow, J.J.; Coleman, M.L.; Newman, D.K. BqsR/BqsS constitute a two-component system that senses extracellular Fe(II) in Pseudomonas aeruginosa. J. Bacteriol. 2012, 194, 1195-1204. [CrossRef]

31. Thaipisuttikul, I.; Hittle, L.E.; Chandra, R.; Zangari, D.; Dixon, C.L.; Garrett, T.A.; Rasko, D.A.; Dasgupta, N.; Moskowitz, S.M.; Malmström, L.; et al. A divergent Pseudomonas aeruginosa palmitoyltransferase essential for cystic fibrosis-specific lipid A. Mol. Microbiol. 2014, 91, 158-174. [CrossRef] [PubMed]

32. McPhee, J.B.; Bains, M.; Winsor, G.; Lewenza, S.; Kwasnicka, A.; Brazas, M.D.; Brinkman, F.S.L.; Hancock, R.E.W. Contribution of the PhoP-PhoQ and PmrA-PmrB two-component regulatory systems to $\mathrm{Mg}^{2+}$-induced gene regulation in Pseudomonas aeruginosa. J. Bacteriol. 2006, 188, 3995-4006. [CrossRef] [PubMed]

33. Zhang, L.; Dhillon, P.; Yan, H.; Farmer, S.; Hancock, R.E.W. Interactions of bacterial cationic peptide antibiotics with outer and cytoplasmic membranes of Pseudomonas aeruginosa. Antimicrob. Agents Chemother. 2000, 44, 3317-3321. [CrossRef] [PubMed]

34. Gooderham, W.J.; Gellatly, S.L.; Sanschagrin, F.; McPhee, J.B.; Bains, M.; Cosseau, C.; Levesque, R.C.; Hancock, R.E.W. The sensor kinase PhoQ mediates virulence in Pseudomonas aeruginosa. Microbiology 2009, 155, 699-711. [CrossRef]

35. Wu, W.; Jin, S. PtrB of Pseudomonas aeruginosa suppresses the type III secretion system under the stress of DNA damage. J. Bacteriol. 2005, 187, 6058-6068. [CrossRef]

36. Xia, Y.; Wang, D.; Pan, X.; Xia, B.; Weng, Y.; Long, Y.; Ren, H.; Zhou, J.; Jin, Y.; Bai, F.; et al. TpiA is a key metabolic enzyme that affects virulence and resistance to aminoglycoside antibiotics through CrcZ in Pseudomonas aeruginosa. mBio 2020, 11, e02079-19. [CrossRef]

37. Deng, X.; Li, M.; Pan, X.; Zheng, R.; Liu, C.; Chen, F.; Liu, X.; Cheng, Z.; Jin, S.; Wu, W. Fis regulates type III secretion system by influencing the transcription of exsA in Pseudomonas aeruginosa strain PA14. Front. Microbiol. 2017, 8, 669. [CrossRef] 
38. Kawasaki, K.; China, K.; Nishijima, M. Release of the lipopolysaccharide deacylase PagL from latency compensates for a lack of lipopolysaccharide aminoarabinose modification-dependent resistance to the antimicrobial peptide polymyxin B in Salmonella enterica. J. Bacteriol. 2007, 189, 4911-4919. [CrossRef]

39. Klebensberger, J.; Rui, O.; Fritz, E.; Schink, B.; Philipp, B. Cell aggregation of Pseudomonas aeruginosa strain PAO1 as an energydependent stress response during growth with sodium dodecyl sulfate. Arch. Microbiol. 2006, 185, 417-427. [CrossRef]

40. Akhoundsadegh, N.; Belanger, C.R.; Hancock, R.E.W. Outer membrane interaction kinetics of new polymyxin B analogs in gram-negative Bacilli. Antimicrob. Agents Chemother. 2019, 63, e00935-19. [CrossRef]

41. Ma, B.; Fang, C.; Lu, L.; Wang, M.; Xue, X.; Zhou, Y.; Li, M.; Hu, Y.; Luo, X.; Hou, Z. The antimicrobial peptide thanatin disrupts the bacterial outer membrane and inactivates the NDM-1 metallo- $\beta$-lactamase. Nat. Commun. 2019, 10, 3517. [CrossRef] [PubMed]

42. Loh, B.; Grant, C.; Hancock, R.E.W. Use of the fluorescent probe 1-N-phenylnaphthylamine to study the interactions of aminoglycoside antibiotics with the outer membrane of Pseudomonas aeruginosa. Antimicrob. Agents Chemother. 1984, 26, 546-551. [CrossRef] [PubMed]

43. Song, M.; Liu, Y.; Huang, X.; Ding, S.; Wang, Y.; Shen, J.; Zhu, K. A broad spectrum antibiotic adjuvant reverses multidrug-resistant Gram-negative pathogens. Nat. Microbiol. 2020, 5, 1040-1050. [CrossRef] [PubMed]

44. Yarlagadda, V.; Akkapeddi, P.; Manjunath, G.B.; Haldar, J. Membrane active vancomycin analogues: A strategy to combat bacterial resistance. J. Med. Chem. 2014, 57, 4558-4568. [CrossRef] [PubMed]

45. Gilleland, H.E.; Stinnett, J.D.; Eagon, R.G. Ultrastructural and chemical alteration of the cell envelope of Pseudomonas aeruginosa, associated with resistance to ethylenediaminetetraacetate resulting from growth in a $\mathrm{Mg}^{2+}$-deficient medium. J. Bacteriol. 1974, 117, 302-311. [CrossRef] [PubMed]

46. Torrens, G.; Barceló, I.M.; Gallego, M.P.; Salom, M.E.; Gracia, S.T.; Bestard, M.M.; Nicolau, M.D.M.G.; Venegas, Y.J.C.; Rumbos, E.N.R.; Cabot, G.; et al. Publisher Correction: Profiling the susceptibility of Pseudomonas aeruginosa strains from acute and chronic infections to cell-wall-targeting immune proteins. Sci. Rep. 2020, 10, 4356. [CrossRef] [PubMed]

47. Lejona, S.; Aguirre, A.; Cabeza, M.L.; Véscovi, E.G.; Soncini, F.C. Molecular characterization of the Mg ${ }^{2+}$-responsive PhoP-PhoQ regulon in Salmonella enterica. J. Bacteriol. 2003, 185, 6287-6294. [CrossRef] [PubMed]

48. Minagawa, S.; Ogasawara, H.; Kato, A.; Yamamoto, K.; Eguchi, Y.; Oshima, T.; Mori, H.; Ishihama, A.; Utsumi, R. Identification and molecular characterization of the $\mathrm{Mg}^{2+}$ stimulon of Escherichia coli. J. Bacteriol. 2003, 185, 3696-3702. [CrossRef] [PubMed]

49. Plesa, M.; Hernalsteens, J.P.; Vandenbussche, G.; Ruysschaert, J.M.; Cornelis, P. The SlyB outer membrane lipoprotein of Burkholderia multivorans contributes to membrane integrity. Res. Microbiol. 2006, 157, 582-592. [CrossRef]

50. Arendt, W.; Hebecker, S.; Jäger, S.; Nimtz, M.; Moser, J. Resistance phenotypes mediated by aminoacyl-phosphatidylglycerol synthases. J. Bacteriol. 2012, 194, 1401-1416. [CrossRef]

51. Barrow, K.; Kwon, D.H. Alterations in two-component regulatory systems of phoPQ and pmrAB are associated with polymyxin B resistance in clinical isolates of Pseudomonas aeruginosa. Antimicrob. Agents Chemother. 2009, 53, 5150-5154. [CrossRef] [PubMed]

52. Fernández, L.; Gooderham, W.J.; Bains, M.; McPhee, J.B.; Wiegand, I.; Hancock, R.E.W. Adaptive resistance to the "last hope" antibiotics polymyxin B and colistin in Pseudomonas aeruginosa is mediated by the novel two-component regulatory system ParR-ParS. Antimicrob. Agents Chemother. 2010, 54, 3372-3382. [CrossRef]

53. Liberati, N.T.; Urbach, J.M.; Miyata, S.; Lee, D.G.; Drenkard, E.; Wu, G.; Villanueva, J.; Wei, T.; Ausubel, F.M. An ordered, nonredundant library of Pseudomonas aeruginosa strain PA14 transposon insertion mutants. Proc. Natl. Acad. Sci. USA 2006, 103, 2833-2838. [CrossRef]

54. Lee, C.C.; Sun, Y.; Qian, S.; Huang, H.W. Transmembrane pores formed by human antimicrobial peptide LL-37. Biophys. J. 2011, 100, 1688-1696. [CrossRef]

55. Darveau, R.P. Lipid A diversity and the innate host response to bacterial infection. Curr. Opin. Microbiol. 1998, 1, 36-42. [CrossRef]

56. Schindler, P.R.; Teuber, M. Action of polymyxin B on bacterial membranes: Morphological changes in the cytoplasm and in the outer membrane of Salmonella typhimurium and Escherichia coli. Antimicrob. Agents Chemother. 1975, 8, 95-104. [CrossRef] [PubMed]

57. Yu, N.Y.; Wagner, J.R.; Laird, M.R.; Melli, G.; Rey, S.; Lo, R.; Dao, P.; Sahinalp, S.C.; Ester, M.; Foster, L.J.; et al. PSORTb 3.0: Improved protein subcellular localization prediction with refined localization subcategories and predictive capabilities for all prokaryotes. Bioinformatics 2010, 26, 1608-1615. [CrossRef]

58. Winsor, G.L.; Griffiths, E.J.; Lo, R.; Dhillon, B.K.; Shay, J.A.; Brinkman, F.S.L. Enhanced annotations and features for comparing thousands of Pseudomonas genomes in the Pseudomonas genome database. Nucleic. Acids Res. 2016, 44, D646-D653. [CrossRef]

59. Qadi, M.; Rabassa, S.I.; Borrás, M.M.; Sánchez, A.D.; Juan, C.; Goldberg, J.B.; Hancock, R.E.W.; Albertí, S. Sensing Mg ${ }^{2+}$ contributes to the resistance of Pseudomonas aeruginosa to complement-mediated opsonophagocytosis. Environ. Microbiol. 2017, 19, 4278-4286. [CrossRef]

60. Ludwig, A.; Tengel, C.; Bauer, S.; Bubert, A.; Benz, R.; Mollenkopf, H.J.; Goebel, W. SlyA, a regulatory protein from Salmonella typhimurium, induces a haemolytic and pore-forming protein in Escherichia coli. Mol. Gen. Genet. 1995, 249, 474-486. [CrossRef] [PubMed]

61. Firoved, A.M.; Deretic, V. Microarray analysis of global gene expression in mucoid Pseudomonas aeruginosa. J. Bacteriol. 2003, 185, 1071-1081. [CrossRef] [PubMed] 
62. Firoved, A.M.; Boucher, J.C.; Deretic, V. Global genomic analysis of AlgU (sigma(E))-dependent promoters (sigmulon) in Pseudomonas aeruginosa and implications for inflammatory processes in cystic fibrosis. J. Bacteriol. 2002, 184, 1057-1064. [CrossRef] [PubMed]

63. Klein, S.; Lorenzo, C.; Hoffmann, S.; Walther, G.M.; Storbeck, S.; Piekarski, T.; Tindall, B.J.; Wray, V.; Nimtz, M.; Moser, J. Adaptation of Pseudomonas aeruginosa to various conditions includes tRNA-dependent formation of alanyl-phosphatidylglycerol. Mol. Microbiol. 2009, 71, 551-565. [CrossRef] [PubMed]

64. Fields, R.N.; Roy, H. Deciphering the tRNA-dependent lipid aminoacylation systems in bacteria: Novel components and structural advances. RNA Biol. 2018, 15, 480-491. [CrossRef] [PubMed]

65. Arendt, W.; Groenewold, M.K.; Hebecker, S.; Dickschat, J.S.; Moser, J. Identification and characterization of a periplasmic aminoacyl-phosphatidylglycerol hydrolase responsible for Pseudomonas aeruginosa lipid homeostasis. J. Biol. Chem. 2013, 288, 24717-24730. [CrossRef] [PubMed] 